\title{
Hybrid Bio-Inspired Computational Heuristic Paradigm for Integrated Load Dispatch Problems Involving Stochastic Wind
}

\author{
Raheela Jamal ${ }^{1}$, Baohui Men ${ }^{1, *}$, Noor Habib Khan ${ }^{1}$ and Muhammad Asif Zahoor Raja ${ }^{2}$ \\ 1 Beijing Key Laboratory of Energy Safety and Clean Utilization, North China Electric Power University, \\ Renewable Energy School, Beijing 102206, China \\ 2 Department of Electrical and Computer Engineering, COMSATS University Islamabad, Attock Campus, \\ Attock 43600, Pakistan \\ * Correspondence: menbh@ncepu.edu.cn; Tel.: +86-010-6177-2451
}

Received: 24 May 2019; Accepted: 1 July 2019; Published: 3 July 2019

\begin{abstract}
In this research work, bio-inspired computational heuristic algorithms (BCHAs) integrated with active-set algorithms (ASA) were designed to study integrated economics load dispatch problems with valve point effects involving stochastic wind power. These BCHAs are developed through variants of genetic algorithms based on a different set of routines for reproduction operators in order to make exploration and exploitation in the entire search space for finding the global optima, while the ASA is used for rapid local refinements of the results. The designed schemes are estimated on different load dispatch systems consisting of a combination of thermal generating units and wind power plants with and without valve point loading effects. The accuracy, convergence, robustness and complexity of the proposed schemes has been examined through comparative studies based on a sufficiently large number of independent trails and their statistical observations in terms of different performance indices.
\end{abstract}

Keywords: integrated power plants systems; economic load dispatch; active-set method; genetic algorithm; wind energy

\section{Introduction}

Economic load dispatch (ELD) is a fundamental issue in power plant systems, design and analysis with the aim of optimal scheduling of generated power in order to satisfy the load demand by least probable cost, while however, fulfilling the constraints on power generators [1-3]. Generally, the electricity generation cost with thermal power plants is excessively high and suitable planning is indeed needed to minimize the cost within reasonable levels. The ELD optimization problem is in one of the difficult constraints-based optimization systems in the power sector that usually needs excessive computations because of the nature of the cost functions and inherent non-smooth properties. A number of studies have introduced a variety of optimization procedures for ELD problems with and without valve point loading effect (VPLE) based on conventional and recently introduced meta-heuristics schemes, such as Newton methods [4,5], genetic algorithms [6], biogeography-based optimization algorithms [7], teaching learning based optimization methods [8], grey-wolf optimization algorithms [9], ant lion optimization procedures [10], modified krill herd algorithms [11,12], natural updated harmony searches [13], improved differential evolution [14], mine blast algorithms [15], and crow-search algorithms [16].

An additional aim in optimal load dispatch is to decrease or reduce the emissions that are dispersed due to the procedure of electricity generation. Normally, these environmental goals are conflicting with the economical nature of the systems, i.e., the decline in emission from generating units (GUs) results 
in the increased rate of electricity generation and vice versa. In such circumstances, multi-objective optimization techniques are exploited for combined ELD with emission problems, such as the symbiotic organisms search optimization method [17], simulated annealing algorithms [18], multi-objective evolutionary computing [19], multi-objective biogeography-based optimization [20], flower pollination algorithms [21], modulated particle swarm optimization [22] and chaotic bat algorithms [23].

The modern trend is to exploit the renewable energy assets for economical and unpolluted generation of electric power by incorporating the electricity generation scheme by use of wind power. The significant advantages of wind energy, besides the one-time initial cost of wind plants, are that there are no costs for production of power through wind, it is more environmentally friendly than thermal power plants and its ease in expendability i.e., installation of additional wind power generating units. There are some renewed applications of ELD involving wind energy, such as the binary artificial sheep method [24], integrated imperialist competitive with sequential quadratic programming [25], fuzzy adaptive artificial physics optimization [26], unit commitment problem involving wind power [27], multi-objective evolutionary algorithm [28] and group search optimizer with multiple producers [29]. All these existing procedures have their own competency, importance, applications and drawbacks in terms of precision, stability, and computing requirements. The research community has growing interest to design, explore and exploit modern stochastic solvers by using the strength of artificial intelligence procedures for applications in the diversified field of applied science and engineering, e.g., solution of stiff optimization problems arising in nanotechnology, nonlinear optics, astrophysics, atomic physics, plasma physics, electromagnetics, fluid mechanics, electric machines, piezoelectric systems, fractional order systems, bioinformatics, signal processing, controls, economic and finance [30-34] along with references therein. Additionally, there are many applications in which evolutionary computing paradigms are exploited through variants of genetic algorithms (GAs) based on different set of routines in the reproduction mechanism [35,36]. All of these are inspiring factors for authors to investigate in evolutionary stochastic paradigms for the solution of the emerging domain of energy and power sectors [37-40] including integrated power plant systems. As per our literature survey, evolutionary computing strategies based on variants of GAs have yet not been exploited in integrated power dispatch problems, therefore, the objective of the present study is to investigate integrated bio-inspired computational heuristic algorithms (BCHAs) based on the variants of GAs aid with the active-set algorithm (ASA) for optimization of load dispatch problems.

A brief summary of innovative contributions in terms of salient features of the proposed study are listed as:

- Novel applications of bio-inspired computational heuristic paradigms integrated with ASA is presented for accurate, stable, robust and efficient optimization of ELD, ELD with VPLE (ELD-VPLE), ELD-VPLE involving stochastic wind (ELD-VPLE-SW) problems.

- Global search strength of GAs and its variants is exploited for the design of BCHAs by using an appropriate set of routines for reproduction operators in order to make exploration of the entire search space supported with speedy local refinements with ASA.

- The performance of the designed schemes is estimated on ELD, ELD-VPLE and ELD-VPLE-SW problems based on a combination of thermal and wind power generating units by means of accuracy, convergence and complexity operators based on the results of statistics for a sufficiently large number of independent trails.

- The effective operation of BCHAs for integrated load dispatch scenarios, and other illustrative hallmarks for simplicity of the concept, coherent procedures with smooth implementation, robustness, expendability and stability.

The optimization procedure of BCHAs is described in Section 1; a brief overview of the system model of the integrated load dispatch system is presented in Section 2; the results with necessary interpretations are given in Section 3, while conclusions with future relevant studies are listed in Section 4. 


\section{Materials and Methods}

\subsection{System Model: Integrated Load Dispatch Problems}

Three type of load dispatch problems are discussed in this study involving the no valve point loading effect (VPLE), with VPLE and VPLE involving stochastic wind power.

The fuel cost function for ELD with no VPLE: The total fuel cost of the power plant $J_{1}$ is modelled in this case with the help of the quadratic cost function and, it is given mathematically as:

$$
J_{1}=\sum_{i=1}^{N_{g}}\left[\left(a_{i}+b_{i} P_{i}+c_{i} P_{i}^{2}\right)\right]
$$

where $N_{g}$ represents the total number of the power plants, $a_{i}, b_{i}$, as well as, $c_{i}$ denote the fuel charge coefficients of $i$ th power plant, and $P_{i}$ gives the current output power of the $i$ th plant.

The fuel cost function for ELD involving VPLE: The total fuel cost of the power plant $J_{1}$ is normally modelled with the help of the quadratic term based cost function, while the valve-point effect is similarly measured through adding of the sinusoidal term. The total fuel cost function is written as follows:

$$
J_{1}=\sum_{i=1}^{N_{g}}\left[\left(a_{i}+b_{i} P_{i}+c_{i} P_{i}^{2}\right)+\left|e_{i .} \cdot \sin \left(f_{i}\left(P_{i \cdot \min }-P_{i}\right)\right)\right|\right],
$$

The coefficient $e_{i}$ and $f_{i}$ denote the fuel charge for the valve-point effect for the $i$ th power plant.

The fuel cost function for ELD with VPLE and stochastic wind power: There are numerous ways that describe the importance of the functioning and forecasting cost in the scheme comprising of both thermal generators, as well as, wind turbines. Subsequently, the instant wind speed is arbitrary at some specified time, therefore, the operator might overestimate or underestimate the wind power availability. The cost function for the wind power generator is given mathematically as: [25]

$$
J_{2}=\sum_{j=1}^{m}\left[\operatorname{WPCost}_{d i r . j}+W P \operatorname{Cost}_{o e . j}+\text { WPCost }_{u e . j}\right]
$$

where, WPCost ${ }_{d i r, j}$ represents the direct cost for the generation of wind power from the $j$ th unit in MWh, WPCost ${ }_{o e, j}$ denotes the overestimation cost for the $j$ th wind generator in MWh and WPCost $t_{u e, j}$ is defined for the underestimation of the cost of $j$ th wind turbine in MWh.

The WPCost dir, $_{j}$ is directly related to the output wind power and it is given as:

$$
\text { WPCost }_{d i r}=\sum_{j=1}^{m}\left(q_{j} \times w_{j}\right)
$$

where, $q_{j}$ and $w_{j}$ are the constant of direct electrical energy generation and real power generated by the $j$ th wind generator in MWh, respectively.

Similarly, the WPCost ${ }_{o e, j}$ can be presented as follows:

$$
\text { WPCost }_{o e, j}=\sum_{j=1}^{m}\left(C_{r w j} \times E\left(Y_{o e, j}\right)\right)
$$

$C_{r w j}$ denotes the charge constant for overestimation and underestimation of the $j$ th wind generator in $\mathrm{MW}$, while $E\left(Y_{o e, j}\right)$ is the expected value of wind power overestimation and underestimation for the $j$ th wind generator. 
The $E\left(Y_{o e, j}\right)$ is mathematically represented as follows: [25]

$$
\begin{aligned}
E\left(Y_{o e, j}\right) & =w_{j}\left[1-\exp \left(\frac{v_{i n, j}^{K j}}{C_{j}^{K K}}\right)+\exp \left(-\frac{v_{o u t, j}^{K j}}{C_{J}^{K j}}\right)\right]+\left(\frac{w_{r, j} v_{i n, j}}{v_{r, j}-v_{i n, j}}+w_{j}\right)\left[\exp \left(-\frac{v_{i n, j}^{K j}}{C_{j}^{K j}}\right)-\exp \left(-\frac{v_{1, j}^{K j}}{C_{j}^{K j}}\right)\right], \\
& +\left(\frac{w_{r, j} C_{j}}{v_{r, j}-v_{i n, j}}\right)\left[\Gamma\left(1+\frac{1}{K_{j}}\left(\frac{v_{1, j}}{C_{j}}\right)^{K j}\right)-\Gamma\left(1+\frac{1}{K_{j}}\left(\frac{v_{i n, j}}{C_{j}}\right)^{K j}\right)\right]
\end{aligned}
$$

where, $K_{j}$ and $C_{j}$ are the shape and scale influence of Weibull distribution intended for the $j$ th wind generator, respectively. The parameters, $v_{r}, v_{\text {in }}$ and $v_{\text {out }}$ stand for wind speed, cut in and cut out speeds in $\mathrm{m} / \mathrm{s}$, respectively. An intermediate constant $v_{1}$ is defined as $v_{1}=v_{\text {in }}+\left(v_{r}-v_{\text {in }}\right) w_{1} / w_{r}$. The wind turbine parameters $w_{j}$ and $w_{r}$ are representing the generated and rated power of the $j$ th plant, respectively. Moreover, in (6), the symbol $\Gamma$ with two parameters represent the incomplete gamma function as:

$$
\Gamma(x, a)=\frac{1}{\Gamma(\mathrm{a})} \int_{0}^{x} t^{a-1} e^{-t} d t,
$$

while, the symbol $\Gamma$ with a single parameter represents the standard gamma function as:

$$
\Gamma(x)=\int_{0}^{x} t^{x-1} e^{-t} d t
$$

Similarly, WPCost $t_{u e, j}$ can be presented as follows:

$$
\operatorname{WPCost}_{u e, j}=\sum_{j=1}^{m}\left(C_{p w j} \times E\left(Y_{u e, j}\right)\right) .
$$

where, $m$ denotes for number of wind generators, $C_{p w i j}$ defines the cost constant of underestimation for the $j$ th wind generator in MWh and $E\left(Y_{u e, j}\right)$ represents as the estimated charge of wind underestimation intended for the $j$ th wind generator, while $E\left(Y_{u e, j}\right)$ is provided mathematically as follows [25]:

$$
\begin{aligned}
E\left(Y_{u e, j}\right)= & \left(w_{r, j}-w_{j}\right)\left[\exp -\left(\frac{v_{r, j}^{K j}}{C_{j}^{K j}}\right)-\exp -\left(\frac{v_{\text {out }, j}^{K j}}{C_{j}^{K j}}\right)\right]+\left(\frac{w_{r, j} v_{i n, j}}{v_{r, j}-v_{i n, j}}+w_{j}\right)\left[\exp \left(-\frac{v_{r, j}^{K j}}{C_{j}^{K j}}\right)-\exp \left(-\frac{v_{1, j}^{K j}}{C_{j}^{K j}}\right)\right] \\
& +\left(\frac{w_{r, j} C_{j}}{v_{r, j}-v_{i n, j}}\right)\left[\Gamma\left(1+\frac{1}{K_{j}}\left(\frac{v_{1, j}}{C_{j}}\right)^{K j}\right)-\Gamma\left(1+\frac{1}{K_{j}}\left(\frac{v_{r, j}}{C_{j}}\right)^{K j}\right)\right]
\end{aligned}
$$

Precisely, the cost function for integrated power plant systems is given as:

$$
\begin{gathered}
J=J_{1}+J_{2} \\
J=\sum_{i=1}^{N_{g}}\left[\left(a_{i}+b_{i} P_{i}+c_{i} P_{i}^{2}\right)+\left|e_{i .} \cdot \sin \left(f_{i}\left(P_{i . \min }-P_{i}\right)\right)\right|\right] \\
+\sum_{j=1}^{m}\left[W P \operatorname{Cost}_{\text {dir. } . j}+W P \operatorname{Cost} t_{o e . j}+\text { WPCost }_{\text {ue. }}\right],
\end{gathered}
$$

where $J_{1}$ is given in Equation (2). Further necessary details of the system model for the interested readers can be seen in [25].

Constraints: The entire power generation based on thermal and wind generators should be equal to $P_{\text {load }}$ line losses $\left(P_{\text {loss }}\right)$ as follows:

$$
\sum_{i=1}^{N g} P_{i}+\sum_{j=1}^{m} w_{j}=P_{\text {load }}+P_{\text {loss }},
$$


where $N_{g}$ represents the amount of power plants, $m$ denotes the number of wind generators, $P_{i}$ describesthe power of the $i$ th power plant. $w_{j}$ represents the generated power of the $j$ th wind, $P_{\text {load }}$ defines the total load demand and $P_{\text {loss }}$ defines the line losses.

The losses of the transmission may be ignored for smaller transmission distance as well as for excessive load densities. However, in an enormous interrelated network wherever power is transferred above the extended distance through low load density regions, losses due to transmission are a foremost issue and distress the optimal dispatch. The mathematical relations of the losses are considered as follows:

$$
P_{\text {loss }}=\sum_{I=1}^{N g} \sum_{j=1}^{N g} P_{i} B_{i j} P_{j}+\sum_{i=1}^{N g} B_{i 0} P_{i}+B_{00}
$$

where, $B_{i j}, B_{i 0}, B_{00}$ is defined as the line loss coefficient and $N_{g}$ represented the number of power plants. The active power of for each power plant, as well as, wind generators must fulfil the following bounds:

$$
\begin{gathered}
P_{i, \min } \leq P_{1} \leq P_{i, \max } \\
0 \leq w_{j} \leq w_{r, j}
\end{gathered}
$$

$P_{i, \min }$ and $P_{i, \max }$ are representing the maximum and minimum parameters of the $i$ th power plant, respectively, while $w_{j}$ and $w_{\mathrm{r}, \mathrm{j}}$ denote the produced and rated power of the $j$ th wind generator, respectively. Basically, the operational collection of the entire generators are restricted through their ramp rate confines. These limits are reflected as follows:

$$
\begin{aligned}
& P_{i}^{0}-P_{i} \leq D_{i} \\
& P_{i}-P_{i}^{0} \leq U_{i}
\end{aligned}
$$

$P_{i}$ and $P_{\mathrm{i}}^{0}$ represent the current and prior output of the $i$ th power plant, respectively, while $D_{i}$ and $U_{i}$ define the down and up ramp rate limits, respectively.

\subsection{Optimization Techniques}

The optimization procedure in this study consists of two parts. In the first part, the design of the bio-inspired heuristic algorithms based on the variant of GAs through its reproduction operators is presented, along with an overview of ASA used for rapid local convergence of the results. While in the second part, the learning procedure of these optimization algorithms to three constrained ELD systems involving VPLE and wind power generators is presented.

GAs is a meta-heuristic algorithm for viable global search and introduced by Holland in the 1970s [41]. GAs work through their fundamental operators of selection, crossover and mutation. These have been effectively utilized in diversified applications of constrained and unconstrained optimization problems with better control, stability, robustness and convergence. The workflow in terms of block structure for GAs is provided in Figure 1, while few potential applications of GAs in power sector can be seen in [42-44]. The steady state optimization performance of GAs is speeded-up by the process of combination with the efficient local search method based on ASA. ASA is one of the best local search procedures for linear and nonlinear, constrained and unconstrained optimization problems. The standard working of ASA is to divide the original stiff problems to relatively non-stiff sub-problems and these sub-problems are solved with the ease of algorithms. The block structure form of the workflow of ASA is shown in Figure 1. ASA addresses effectively many optimization problems which include nonnegative matrix factorization problems [45], variation deblurring problems [46] and warehouse location problems [47]. 


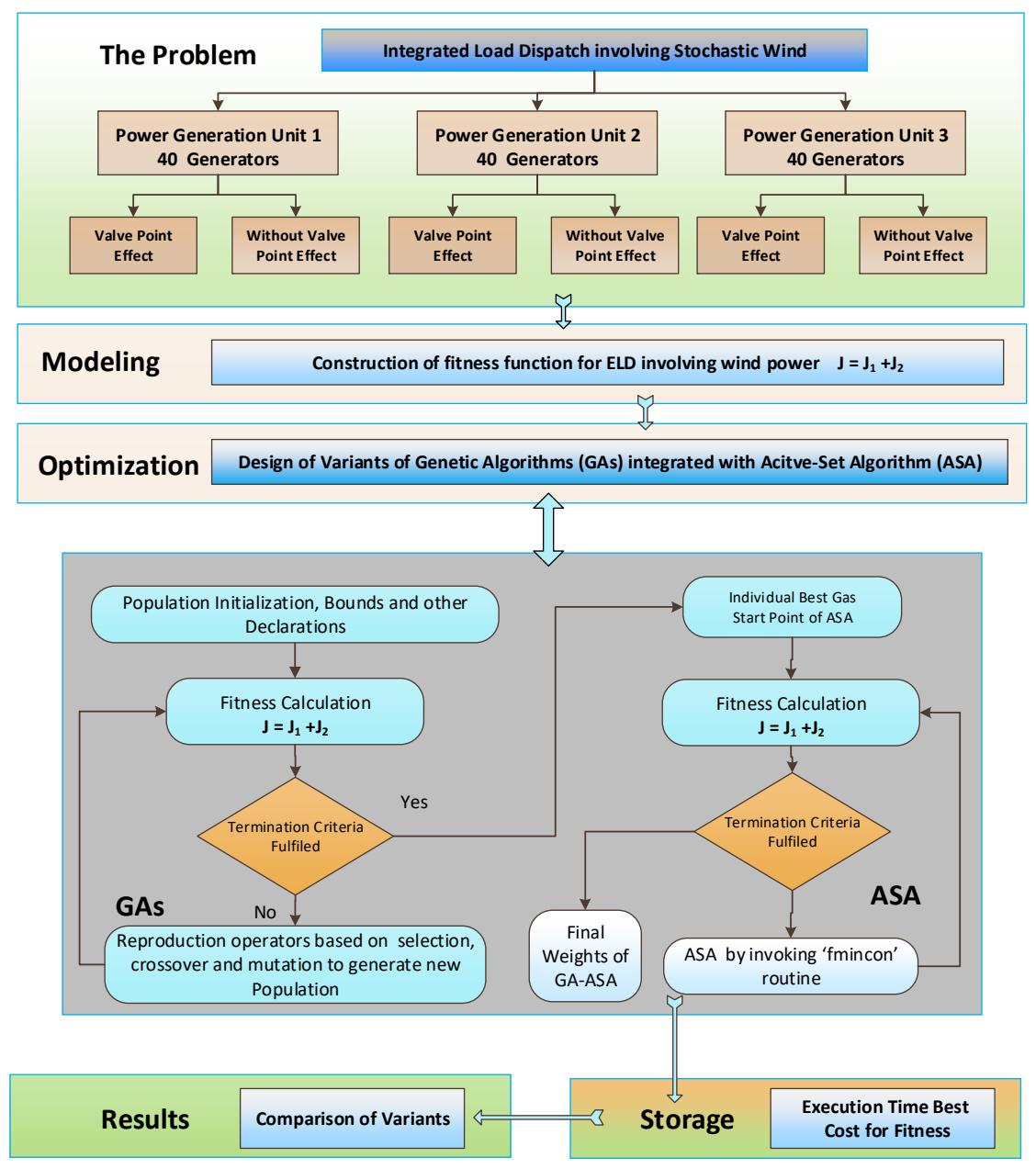

Figure 1. Graphical overview of the proposed design schemes for solving integrated economic load dispatch problems involving stochastic wind.

The paramount importance of GAs and ASA has encouraged the use of memetic variants of GAs with ASA (GA-ASA) for integrated load dispatch problems. Nine different sequential computing paradigms, GA-ASA-1 to GA-ASA-9 are designed for optimization based on a different set of reproduction operators as provided in Table 1 . The selection operator stochastic uniform, means that GAs move along the line in steps of equal size. The section operator reminder, means that the probability for the selection of the parent is proportional to the fractional part of its scaled value. The selection operator roulette, means that an individual is chosen randomly with a probability equal to their respective area. The crossover operator heuristic, means an offspring that lies on the line containing their parents. The crossover operator arithmetic, means the create/generate offspring that are the weighted arithmetic mean of their parents. The crossover operator scatter, means a random one point, two point or intermediate crossover between the genes of two parents to have new child. The mutation operator adaptive feasible, means randomly generated feasible directions according to the last known successful or unsuccessful generation. The workflow diagram of the proposed approach is presented in Figure 1. In this study, implementation of variants of GAs and ASA is made through the optimization toolbox of the software package, Matlab with the help of ga, gaoptimset, fmincon and optimset routines. All three load dispatch problems are solved by these functions with appropriate settings of the parameters. The pseudocode of ASA is given in Algorithm 1. 


\begin{tabular}{l} 
Algorithm 1: Active-set Algorithm (ASA) \\
\hline Inputs:
\end{tabular}

The best individual of nine variants of GAs for each ELD, ELD-VPLE and ELD-VPLE-SW in the case involving 40 generation units. Mathematically represented as:

$$
P_{\mathrm{GA}}= \begin{cases}{\left[P_{1}, P_{2}, \ldots, P_{40}\right]} & \text { ELD } \\ {\left[P_{1}, P_{2}, \ldots, P_{40}\right]} & \text { ELD - VPLE } \\ {\left[P_{1}, P_{2}, \ldots, P_{37}, \mathrm{~W}_{1}, \mathrm{~W}_{2}, \mathrm{~W}_{3}\right]} & \text { ELD - VPLE - SW }\end{cases}
$$

Output: The refined weights by ASA represented as:

$$
P_{\mathrm{GA}-A S M}= \begin{cases}{\left[P_{1}, P_{2}, \ldots, P_{40}\right]} & \text { ELD } \\ {\left[P_{1}, P_{2}, \ldots, P_{40}\right]} & \text { ELD - VPLE } \\ {\left[P_{1}, P_{2}, \ldots, P_{37}, \mathrm{~W}_{1}, \mathrm{~W}_{2}, \mathrm{~W}_{3}\right]} & \text { ELD - VPLE - SW }\end{cases}
$$

\section{Initialization:}

Initialize the values of random assignments, constraints and parameters of the ASA.

\section{Termination:}

Set stopping requirement of ASA as follows:

Maximum iterations/cycles i.e., 1000,

Tolerances

$$
\begin{aligned}
& \text { TolFun, i.e., } 10^{-12}, \\
& \text { TolCon, i.e., } 10^{-12}, \\
& \text { TolX) values, i.e., } 10^{-10},
\end{aligned}
$$

While \{Stopping criteria achieved\} do

\section{Cost calculation:}

Calculate the cost using Equations (1)-(3) for ELD, ELD-VPLE and ELD-VPLE-SW for 40 generating units

Stoppage

If any of termination is achieved, then exit from the loop, or else it continues.

\section{Refinements}

Refine the values of the decision variables at each iteration with ASA using the fmincong routine with algorithm active-set in the MATLAB optimization toolbox.

End

\section{Storage}

Store the values of decision variables for ELD, ELD-VPLE and ELD-VPLE-SW along with their costs, time, function count for current execution of ASA.

Statistics: Repeat the steps from initialization to storage for 100 trials for all nine variants of GA, i.e., GA-1 to GA-9 to generate a dataset of GA-ASA-1 to GA-ASA-9 results for comparative analysis of performance.

Table 1. The functions invoke to design the variants of the proposed optimization solvers based on genetic algorithms (GAs) supported with the active-set algorithm (ASA).

\begin{tabular}{ccccc}
\hline \multirow{2}{*}{ Methods } & \multicolumn{2}{c}{ Invoke Routines of Reproduction Operators } & Aided with \\
\cline { 2 - 5 } & Selection & Crossover & Mutations & 'ASA' \\
\hline GA-1 & "Stochastic Uniform" & "Heuristic" & "Adaptive Feasible" & GA-ASA-1 \\
GA-2 & "Stochastic Uniform" & "Arithmetic" & "Adaptive Feasible" & GA-ASA-2 \\
GA-3 & "Stochastic Uniform" & "Scattered" & "Adaptive Feasible" & GA-ASA-3 \\
GA-4 & "Reminder" & "Heuristic" & "Adaptive Feasible" & GA-ASA-4 \\
GA-5 & "Reminder" & "Arithmetic" & "Adaptive Feasible" & GA-ASA-5 \\
GA-6 & "Reminder" & "Scattered" & "Adaptive Feasible" & GA-ASA-6 \\
GA-7 & "Roulette" & "Heuristic" & "Adaptive Feasible" & GA-ASA-7 \\
GA-8 & "Roulette" & "Arithmetic" & "Adaptive Feasible" & GA-ASA-8 \\
GA-9 & "Roulette" & "Scattered" & "Adaptive Feasible" & GA-ASA-9 \\
\hline
\end{tabular}




\section{Results and Discussion}

The numerical experimentation of the all nine design schemes for three load dispatch problems based on 40 generation units (40-GUs) involving no VPLE, with VPLE and combined thermal, as well as, wind GUs with VPLE are presented in this section. The nine variants of GA were applied initially and later on, all the results of these variants were given to ASA for further refinements. The load demand (PD) remained fixed at 10,500 MW for all three load dispatch problems. The maximum generators output powers Pmax, the minimum generators output powers Pmin and the cost coefficients in the case of 40 GUs are given in Appendix A [48]. The parameter of wind GUs is given in Appendix B [25,49].

Cost function formulation: The cost function for ELD problems with 40 GUs, i.e., $N_{g}=40$, having quadratic cost function using Equation (1), is written as:

$$
J_{1}=\sum_{i=1}^{40}\left[\left(a_{i}+b_{i} P_{i}+c_{i} P_{i}^{2}\right)\right]
$$

where the values of Pmin, Pmax and cost coefficients vectors $\boldsymbol{a}, \boldsymbol{b}$ and $\boldsymbol{c}$ are given in Table A1 of Appendix A. The constraints associated with the problem are written as:

$$
\mathrm{PD}=\sum_{i=1}^{40} P_{i}=10500, \quad P_{i, \min } \leq P_{i} \leq P_{i, \max }
$$

Similarly, the cost function for ELD problems with VPLE (ELD-VPLE) for $40 \mathrm{GUs}$, i.e., $N_{g}=40$, is written as:

$$
J=\sum_{i=1}^{40}\left[\left(a_{i}+b_{i} P_{i}+c_{i} P_{i}^{2}\right)+\left|e_{i .} \cdot \sin \left(f_{i}\left(P_{i \cdot \min }-P_{i}\right)\right)\right|\right],
$$

where the values of $P_{\min }, P_{\max }$ along with cost coefficients vectors $\boldsymbol{a}, \boldsymbol{b}, \boldsymbol{c}, \boldsymbol{e}$ and $\boldsymbol{f}$ are given in Table A1 of Appendix A. The constraints associated with the problem are given in Equation (16).

The cost function for ELD problems involving VPLE by considering stochastic wind availability (ELD-VPLE-SW), in the case of 3 wind GUs, i.e., $\mathrm{m}=3$, and 37 thermal $\mathrm{GUs}, \mathrm{Ng}=37$, are given as:

$$
\begin{aligned}
J= & \sum_{i=1}^{37}\left[\left(a_{i}+b_{i} P_{i}+c_{i} P_{i}^{2}\right)+\left|e_{i .} \cdot \sin \left(f_{i}\left(P_{i . \min }-P_{i}\right)\right)\right|\right] \\
& +\sum_{j=1}^{3}\left[\text { WPCost }_{\text {dir. } . j}+\text { WPCost }_{\text {oe. } j}+\text { WPCost }_{\text {ue. } . j}\right]
\end{aligned}
$$

where the values of $P_{\min }, P_{\max }$ and cost coefficients vectors $\boldsymbol{a}, \boldsymbol{b}, \boldsymbol{c}, \boldsymbol{e}$ and $\boldsymbol{f}$ are given in Table A1 of Appendix A, while the parameter of wind generating units is given in Table A2 of Appendix B. The constraints associated with the problem are given in Equation (16).

The design nine variants of GA were applied to solve ELD, ELD-VPLE and ELD-VPLE-SW problems using the cost function given in Equations (15), (17) and (18), respectively, while satisfying the constraints given in Equation (16). The learning curves of GA-1 along its fitness value and output power are shown graphically in Figure 2a,c,e for ELD, ELD-VPLE and ELD-VPLE-SW problems, respectively. The global best weights of GA-1 for all three load dispatch problems are given to ASA for further refinements and respective results of GA-ASA-1 in Figure $2 b, d$,f. It can be seen that by the process of combination, a significant improvement in the values of the cost function was observed for all three load dispatch problems. Accordingly, the results of all nine variants of GA and GA-ASA were determined. The results of in terms of costs, time consumed, generation (Gen) executed, and fitness function evaluated (FE) are given in Table 2 for ELD, ELD-VPLE and ELD-VPLE-SW problems, while the results of output power Pi of GA and GA-ASA for all three load dispatch problems ELD, ELD-VPLE and ELD-VPLE-SW are listed in Tables A3-A5, respectively, of Appendix C. For ELD problems without considering VPLE, the minimum cost was achieved by GA-4 and the worst cost was achieved by GA-8, 
while no noticeable difference in time, generation (Gen) and function evaluated (FE) were observed (see data presented in Table 2). However, in the process of sequential computing the nine variants of GA-ASA, all nine algorithms converged to the same minimum cost. This is understandable given the ELD problems based on smooth/convex cost functions with unique local minima (see the results listed in Table 2).
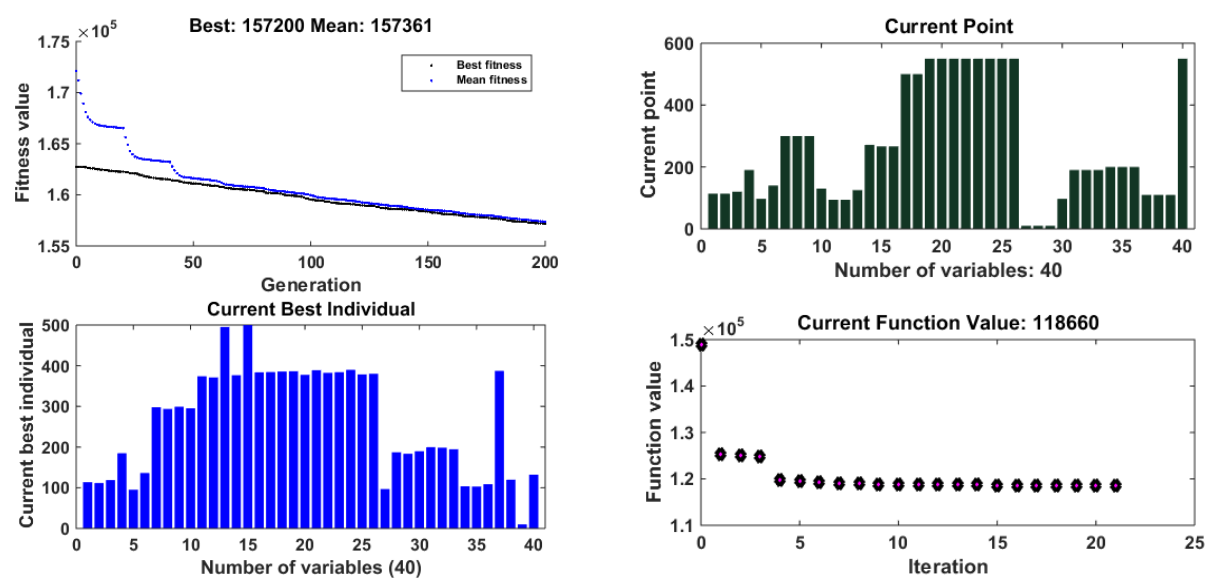

(a) The results of GA-1 with no VPLE

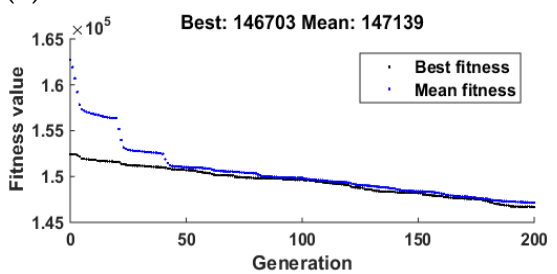

(b) The results of GA-ASA-1 with no VPLE
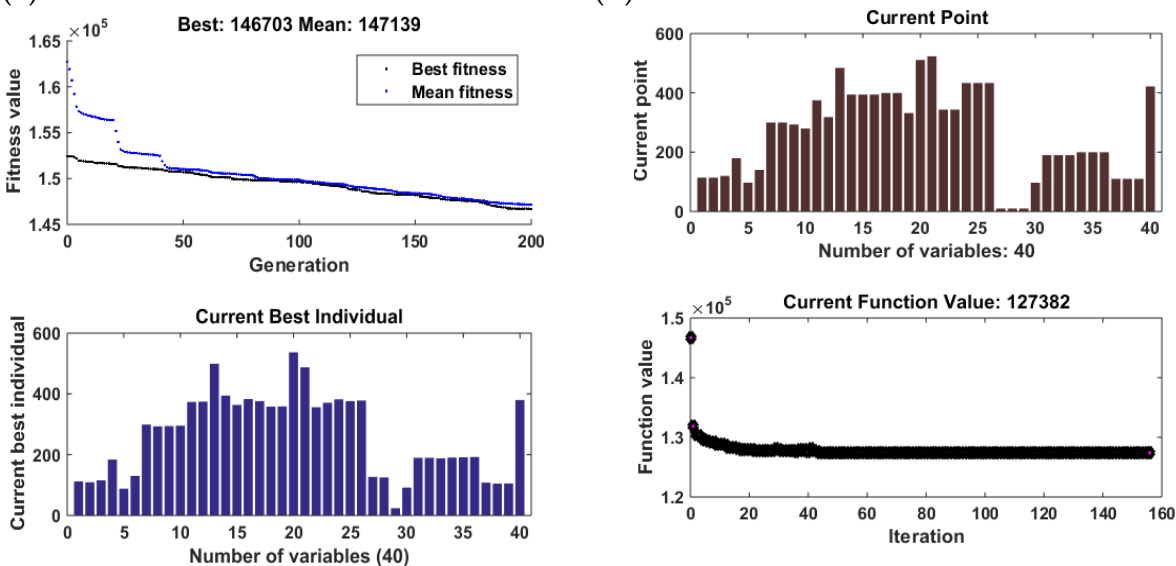

(c) The results of GA-1 with VPLE

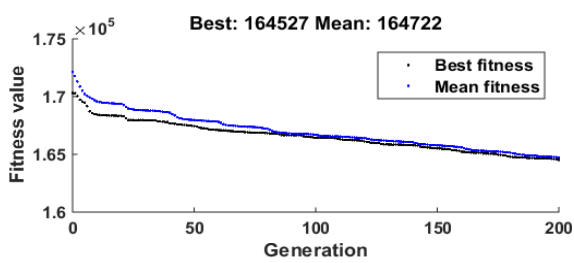

(d) The results of GA-ASA-1 with VPLE
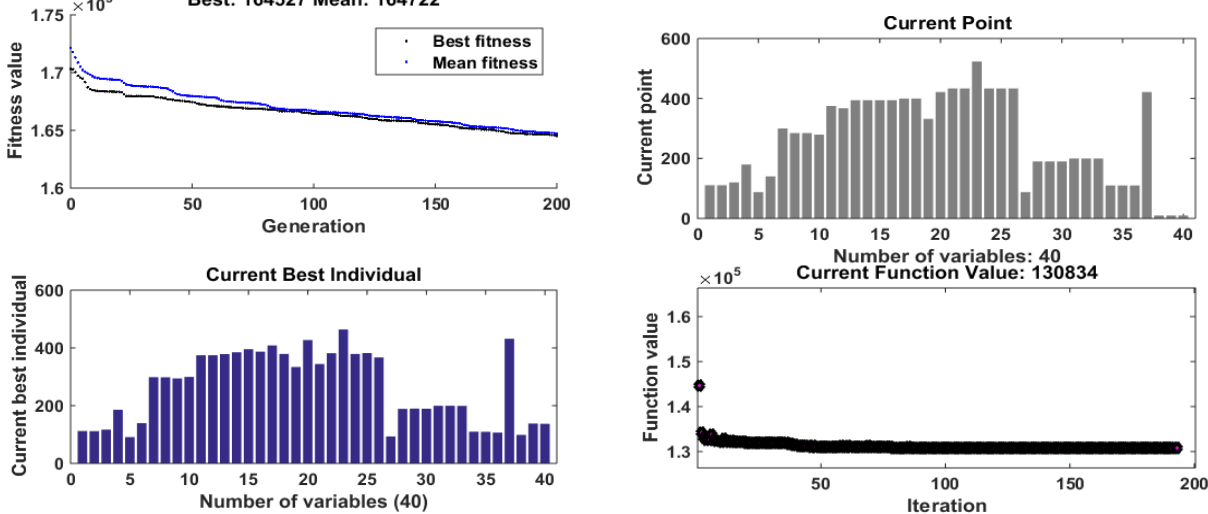

(e) The results of GA-1 for VPLE-SW

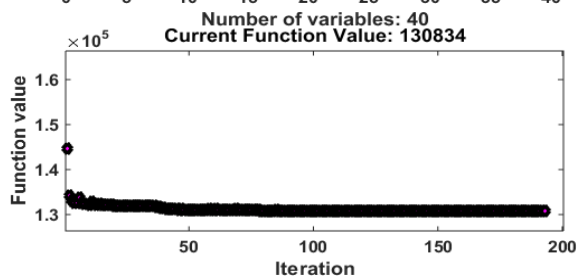

(f) The results of GA-ASA-1 for VPLE-SW

Figure 2. The adaptation of parameters of ELD systems based on 40 generating unit without considering VPLE, with considering VPLE and VPLE-SW.

Apart from the comparison of nine variants of GA and GA-ASA with each other, a detailed analysis of the proposed results in both cases of ELD-VPLE for 40GUs system and integrated power plant systems, i.e., ELD-VPLE-SW for 40GUs system with 3 wind units, is made with reported 
results. In the case of ELD-VPLE-SW, the results of reported solutions with Hybrid imperialist competitive-sequential quadratic programming (HIC-SQP) [25], PWTED1 [50], DWTED1 [50] and best compromise [50] are listed in Table 3. The best results were reported in HIC-SQP [25] for ELD-VPLE-SW based on the integrated load dispatch problem. Similarly, was the case for ELD-VPLE reported solutions for evolutionary programming aided with sequential quadratic programming (EP-SQP) [51], HIC-SQP [25], ant colony optimization (ACO) [52], biogeography-based optimization (BBO) [53], differential evolution aided with BBO (DE-BBO) [53], bacterial foraging optimization combined with Nelder-Mead (BF-NM) [54], new particle swarm optimization supported with local random searches (NPSO-LRS) [55] and real coded genetic algorithms (RCGA) [56]. The minimum cost achieved by HIC-SQP, PWTED1 and DWTED1 methods are listed in Table 3 for ELD-VPLE-SW, while the minimum costs of ES-SQP, HIC-SQP, ACO, BBO, DE-BBO, BF-NM, NPSO-LRS and RCGA for ELD-VPLE problems are also presented in Table 3. In the case of ELD-VPLE, the reported and our sequential computing algorithms have close resemblance with standard solutions, however none of the variants of GAs, GA-1 to GA-9 and their memetic computing techniques, i.e., GA-ASA-1 to GA-ASA-9, give the best solution reported so far for ELD-VPLE problems. Whereas, the significance of the proposed algorithms was evidently seen in the case of ELD-VPLE-SW problems based on the stiff cost function as defined in Equation (18), involving the calculation of incomplete gamma functions for each evaluation of the objective function. For example, the result achieved by the integrated computing approach GA-ASA-2 was $127,345.345 \$ / \mathrm{h}$, which was better than the best reported optimization solutions for ELD-VPLE-SW problems in [25]. Additionally, it was observed that the proposed results of all nine variants of GA were poorer than in the reported results. However, after performance with ASA, the results of all nine variants of GA-ASA improved considerably, and even better than the reported results of recently applied algorithms based on HIC-SQP, PWTEDI, DWTEDI and best compromise.

Table 2. The results of GA and GA-ASA for ELD problems based on 40 GUs without considering VPLE, considering VPLE and integration of wind units.

\begin{tabular}{|c|c|c|c|c|c|c|c|c|c|c|c|c|}
\hline Method & \multicolumn{4}{|c|}{ Without VPLE } & \multicolumn{4}{|c|}{ With VPLE } & \multicolumn{4}{|c|}{ VPLE and Stochastic Wind } \\
\hline GA-1 & 132,514 & 90 & 200 & 30,150 & 137,359 & 97 & 200 & 30,150 & 147,325 & 115 & 200 & 30,150 \\
\hline GA-3 & 138,246 & 98 & 200 & 30,150 & 146,458 & 90 & 200 & 30,150 & 157,408 & 95 & 200 & 30,150 \\
\hline GA-4 & 131,173 & 103 & 200 & 30,150 & 137,920 & 91 & 200 & 30,150 & 152,326 & 103 & 200 & 30,150 \\
\hline GA-7 & 133,351 & 88 & 200 & 30,150 & 139,825 & 101 & 200 & 30,150 & 148,987 & 101 & 200 & 30,150 \\
\hline GA-8 & 140,843 & 81 & 200 & 30,150 & 146,693 & 94 & 200 & 30,150 & 158,070 & 113 & 200 & 30,150 \\
\hline GA-9 & 139,700 & 100 & 200 & 30,150 & 145,944 & 88 & 200 & 30,150 & 157,778 & 99 & 200 & 30,150 \\
\hline GA-ASA-1 & 118,660 & 91 & 221 & 31,851 & 122,749 & 105 & 342 & 28,861 & 127,611 & 132 & 350 & 29,939 \\
\hline GA-ASA-2 & 118,660 & 82 & 224 & 32,094 & 122,719 & 100 & 324 & 27,325 & 127,744 & 143 & 237 & 20,288 \\
\hline GA-ASA-7 & 118,660 & 89 & 221 & 31,851 & 123,062 & 106 & 210 & 17,498 & 127,257 & 132 & 500 & 41,167 \\
\hline GA-ASA-8 & 118,660 & 82 & 221 & 31,852 & 122,796 & 104 & 343 & 29,568 & 127,038 & 122 & 204 & 16,916 \\
\hline GA-ASA-9 & 118,660 & 101 & 221 & 31,851 & 122,646 & 93 & 205 & 17,054 & 127,392 & 109 & 220 & 18,474 \\
\hline
\end{tabular}

Table 3. The comparison of reported solutions in case of 40 thermal generating without VPLE and with VPLE.

\begin{tabular}{cccccc}
\hline Algorithm & ELD-VPLE & Algorithm & ELD-VPLE & Algorithm & ELD-VPLE-SW \\
\hline EP-SQP & $122,324.00 \$ / \mathrm{h}$ & BBO & $121,688.6634 \$ / \mathrm{hr}$ & HIC-SQP & $136,381.3831 \$ / \mathrm{h}$ \\
HIC-SQP & $121,418.23 \$ / \mathrm{hr}$ & BF-NM & $121,423.63 \$ / \mathrm{hr}$ & PWTEDI & $137,985.38 \$ / \mathrm{h}$ \\
NPSO-RLS & $123,094.98 \$ / \mathrm{hr}$ & DE-BBO & $121,420.89 \$ / \mathrm{hr}$ & DWTEDI & $137,190.31 \$ / \mathrm{h}$ \\
ACO & $121,679.64 \$ / \mathrm{hr}$ & RCGA & $121,628.59 \$ / \mathrm{hr}$ & Best compromise & $143,587.90 \$ / \mathrm{h}$ \\
\hline
\end{tabular}


The analysis on multiple run of algorithms: The performance analysis on the basis of multiple runs for all nine variants of GA and GA-ASA were carried out to solve the optimization problems based on ELD, ELD-VPLE and ELD-VPLE-SW systems which consisted of 40 Gus, including both thermal and wind power plants.

The analysis on the precision and reliability were performed through a hundred independent trails of each variant of GA and GA-ASAs in order to optimize all three load dispatch problems. The results for GA-1 and GA-ASA-1 in terms of best cost against the number of runs of the algorithms for ELD, ELD-VPLE and ELD-VPLE-SW systems are shown in Figure 3a,b, respectively, while the histogram plots of GA-1 to solve the ELD, ELD-VPLE, and ELD-VPLE-SW are shown in Figure 3c-e, respectively, and respective histogram plots for GA-ASA- 1 algorithms are plotted in Figure $3 \mathrm{f}-\mathrm{h}$. Accordingly, the best cost against number of runs along with their histogram studies were conducted for all three load dispatch problems for GA-2 and GA-3 as well as GA-ASA-2 and GA-ASA-3. Similarly, the results of the cost against the number of runs are shown in Figure 4 for GA-4 and GA-ASA-4, while in Figure 5 for GA-8 and GA-ASA-8. From Figure 3, a small variation in the values of GA-1 was observed for all the load dispatch models while such small oscillations were also evident in solving ELD-VPLE and ELD-VPLE-SW systems by GA-ASA-1. However, no variations were seen in ELD problems optimized with GA-ASA-1. The results in Figure 3 also showed that the same trend of GA-1 and GA-ASA- 1 were followed by GA-2 to GA-3 and GA-ASA-2 to GA-ASA-3, respectively, for all three ELD, ELD-VPLE, ELD-VPLE-SW power generation systems. Accordingly, the similar behavior of the results is evidently seen from the rest of the illustrations presented in Figures 4 and 5.

The results presented in the histogram illustrations of Figure 3 showed that approximately $19 \%$, $18 \%$ and $17 \%$ of the runs of GA- 1 achieved costs $\leq 1.467 \times 10^{5}, 1.5151005$ and $1.637 \times 10^{5}$ for ELD, ELD-VPLE, ELD-VPLE-SW power generation systems, respectively. However, $100 \%, 17 \%$ and $19 \%$ of the runs GA-ASA- 1 obtained the cost $\leq 1.187 \times 10^{5}, 1.254 \times 10^{5}$ and $1.301 \times 10^{5}$ for three respective load dispatch models. The results revealed that approximately $15 \%, 14 \%$ and $12 \%$ of the runs of GA-2 achieved the costs $\leq 1.526 \times 10^{5}, 1.576 \times 10^{5}$ and $1.679 \times 10^{5}$ for ELD, ELD-VPLE, ELD-VPLE-SW power generation systems, respectively, while $100 \%, 15 \%$ and $14 \%$ of the runs GA-ASA-2 obtained the costs $\leq 1.187 \times 10^{5,} 1.252 \times 10^{5}$ and $1.297 \times 10^{5}$ for three respective load dispatch models. The results with similar observations were achieved by GA-3 to GA-9 as well as GA-ASA-3 to GA-ASA-9. Thus, it can be concluded that generally for non-smooth, as well as smooth cost functions of power dispatch problems, the memetic computing approaches, i.e., GA-ASA-1 to GA-ASA-9, provided relatively better results than the standalone approaches, i.e., GA-1 to GA-9.

Complexity Analysis: The complexity analysis for all nine variants of GA and GA-ASAs are presented in terms of time consume, generation (Gen)/iteration executed and cost function evaluated /counted (FCs) for all three load dispatch systems. The result of complexity operators based on the mean along with its standard deviations (STD) magnitudes are presented in Table 4 for ELD, ELD-VPLE, ELD-VPLE-SW power generating systems in each case of GA and GA-ASAs. Regarding the ELD problem without VPLE, cost, time, Gen and FCs were 147,196 $\pm 4373,92 \pm 9,174 \pm 14$ and $27,126 \pm 6754$ for GA, while for GA-ASA values of cost, time, Gen, FCs were 118,660 $\pm 0,94 \pm 12$, $196 \pm 7$, and 28,036 \pm 144 . The cost, time, Gen and FCs were 152,000 $\pm 4000,94 \pm 10,199 \pm 20$ and $29,000 \pm 4000$ for GA for ELD by considering VPLE, while for GA-ASA values of cost, time, Gen, FCs were 125,000 $\pm 1000,95 \pm 9,428 \pm 91$ and 47,534 \pm 7378 . For ELD problems based on VPLE-SW, cost, time, Gen and FCs were 163,788.43 $\pm 4772.70,98.37 \pm 10.65,173.60 \pm 41.13$ and 26,190.00 \pm 222.00 for GA, while for GA-ASA the values of cost, time, Gen, FCs were 129,676.74 \pm 897.77, $110.05 \pm 11.23$, $424.41 \pm 83.55$, and $47,214.99 \pm 7472.99$. The time based complexity analysis of the proposed variants GA-1 to GA-9, as well as, GA-ASA-1 to GA-ASA-9 is dependent on the specification of the machine on which optimization algorithms are executed. Thus, for better processing platforms, the computing time of optimization of the decision variable is reduced and vice versa. Similarly, varied computational requirement are associated with single generation/cycle of meta-heuristic paradigm based on GAs. Therefore, generations/iterations are also not effective for measurement of the complexity. To overcome 
these issues, the number of fitness function evaluated during the process of optimization of decision variables has been used as a measure for the analysis of the complexity which is a machine independent gauge. The complexity of the variants is given on the basis of time, iterations and FCs in the current study. These values are used for comparison whenever the same problems are addressed with counterpart meta-heuristic methodologies. The reported values of complexity in terms of time in seconds for the execution of a single generation/iteration were given 0.0597 for HIC-SQP [25] for ELD-VPLE-SW problems based on 37 thermal and three wind turbines based generated units. The CPU time per iteration of HIC-SQP [25] was better than reported PWTED1 [50], DWTED1 [50] and best compromise [50]. The similarly calculated values of complexity measure of proposed variants also provided the consumed time in close vicinity of the reported results.

Table 4. The comparison of results for ELD problems without considering VPLE, with considering VPLE and VPLE-SW through statistical performance indices.

\begin{tabular}{|c|c|c|c|c|c|c|c|c|c|}
\hline \multirow{2}{*}{ Index } & \multirow{2}{*}{ Method } & \multicolumn{4}{|c|}{ Mean } & \multicolumn{4}{|c|}{ STD } \\
\hline & & Cost & Time & Gen & FCs & Cost & Time & Gen & FCs \\
\hline \multirow[t]{18}{*}{ No VPLE } & GA-1 & 147,125 & 92 & 200 & 30,150 & 4414 & 17 & 0 & 0 \\
\hline & GA-2 & 152,431 & 87 & 180 & 27,126 & 4739 & 8 & 43 & 6481 \\
\hline & GA-3 & 151,484 & 93 & 200 & 30,150 & 4897 & 13 & 0 & 0 \\
\hline & GA-4 & 145,951 & 96 & 200 & 30,150 & 4970 & 12 & 0 & 0 \\
\hline & GA-5 & 152,831 & 88 & 169 & 25,478 & 4482 & 12 & 52 & 7865 \\
\hline & GA-6 & 151,240 & 94 & 199 & 29,936 & 5034 & 11 & 14 & 2145 \\
\hline & GA-7 & 147,196 & 96 & 200 & 30,150 & 4261 & 9 & 0 & 0 \\
\hline & GA-8 & 152,119 & 91 & 174 & 26,309 & 4373 & 16 & 45 & 6754 \\
\hline & GA-9 & 150,732 & 91 & 199 & 30,050 & 4994 & 7 & 7 & 1005 \\
\hline & GA-ASA-1 & 118,660 & 92 & 221 & 31,880 & 0 & 17 & 2 & 126 \\
\hline & GA-ASA-2 & 118,660 & 88 & 202 & 28,905 & 0 & 8 & 43 & 6471 \\
\hline & GA-ASA-3 & 118,660 & 94 & 221 & 31,877 & 0 & 13 & 2 & 148 \\
\hline & GA-ASA-4 & 118,660 & 96 & 222 & 31,897 & 0 & 12 & 2 & 144 \\
\hline & GA-ASA-5 & 118,660 & 89 & 191 & 27,252 & 0 & 12 & 52 & 7861 \\
\hline & GA-ASA-6 & 118,660 & 95 & 220 & 31,676 & 0 & 11 & 14 & 2137 \\
\hline & GA-ASA-7 & 118,660 & 97 & 221 & 31,882 & 0 & 9 & 2 & 137 \\
\hline & GA-ASA-8 & 118,660 & 92 & 196 & 28,036 & 0 & 16 & 45 & 6758 \\
\hline & GA-ASA-9 & 118,660 & 92 & 221 & 31,799 & 0 & 7 & 7 & 1012 \\
\hline \multirow[t]{18}{*}{ VPLE } & GA-1 & 151,927 & 97 & 200 & 30,150 & 4662 & 11 & 0 & 0 \\
\hline & GA-2 & 157,187 & 90 & 183 & 27,611 & 4764 & 13 & 44 & 6567 \\
\hline & GA-3 & 156,530 & 90 & 199 & 29,960 & 5076 & 11 & 13 & 1905 \\
\hline & GA-4 & 153,248 & 97 & 200 & 30,150 & 4392 & 13 & 0 & 0 \\
\hline & GA-5 & 158,020 & 88 & 183 & 27,662 & 4735 & 8 & 41 & 6083 \\
\hline & GA-6 & 157,193 & 97 & 199 & 29,955 & 4814 & 12 & 13 & 1950 \\
\hline & GA-7 & 152,499 & 98 & 200 & 30,150 & 4590 & 10 & 0 & 0 \\
\hline & GA-8 & 158,255 & 93 & 185 & 27,929 & 4482 & 16 & 40 & 5975 \\
\hline & GA-9 & 157,775 & 94 & 200 & 30,150 & 4611 & 7 & 0 & 0 \\
\hline & GA-ASA-1 & 125,528 & 103 & 445 & 51,028 & 1206 & 11 & 76 & 6701 \\
\hline & GA-ASA-2 & 125,137 & 95 & 428 & 48,342 & 1194 & 13 & 90 & 9677 \\
\hline & GA-ASA-3 & 125,381 & 97 & 454 & 51,574 & 1196 & 12 & 97 & 8408 \\
\hline & GA-ASA-4 & 125,238 & 104 & 459 & 52,228 & 1223 & 13 & 95 & 8366 \\
\hline & GA-ASA-5 & 125,072 & 94 & 433 & 48,842 & 1218 & 9 & 83 & 8732 \\
\hline & GA-ASA-6 & 125,287 & 102 & 453 & 51,564 & 1236 & 12 & 91 & 8065 \\
\hline & GA-ASA-7 & 125,657 & 104 & 444 & 50,849 & 1060 & 10 & 74 & 6405 \\
\hline & GA-ASA-8 & 125,411 & 99 & 416 & 47,534 & 1146 & 16 & 85 & 8818 \\
\hline & GA-ASA-9 & 125,375 & 100 & 445 & 50,903 & 1171 & 7 & 88 & 7378 \\
\hline \multirow[t]{10}{*}{ VPLE-SW } & GA-1 & 163,557 & 108 & 200 & 30,150 & 5362 & 11 & 0 & 0.00 \\
\hline & GA-2 & 167,796 & 98 & 171 & 25,747 & 4834 & 12 & 51 & 7741 \\
\hline & GA-3 & 167,815 & 102 & 200 & 30,150 & 4580 & 9 & 0.00 & 0 \\
\hline & GA-4 & 163,848 & 108 & 200 & 30,150 & 4817 & 150 & 0 & 0 \\
\hline & GA-5 & 167,456 & 99 & 173 & 26,190 & 4772 & 11 & 46 & 6932 \\
\hline & GA-6 & 167,024 & 105 & 200 & 30,150 & 5090 & 16 & 0 & 0 \\
\hline & GA-7 & 163,788 & 108 & 200 & 30,150 & 4841 & 12 & 0 & 0 \\
\hline & GA-8 & 167,120 & 98 & 180 & 27,130 & 5146 & 10 & 41 & 6169 \\
\hline & GA-9 & 167,539 & 103 & 199 & 29,928 & 4738 & 9 & 14 & 2220 \\
\hline & GA-ASA-1 & 130,102 & 110 & 436 & 50,183 & 901 & 11 & 77 & 6565 \\
\hline
\end{tabular}


Table 4. Cont.

\begin{tabular}{|c|c|c|c|c|c|c|c|c|c|}
\hline \multirow{2}{*}{ Index } & \multirow{2}{*}{ Method } & \multicolumn{4}{|c|}{ Mean } & \multicolumn{4}{|c|}{ STD } \\
\hline & & Cost & Time & Gen & FCs & Cost & Time & Gen & FCs \\
\hline \multirow[t]{8}{*}{ VPLE-SW } & GA-ASA-2 & 129,706 & 109 & 424 & 47,214 & 975 & 13 & 101 & 10,589 \\
\hline & GA-ASA-3 & 129,828 & 114 & 448 & 51,198 & 955 & 10 & 89 & 7450 \\
\hline & GA-ASA-4 & 130,075 & 120 & 445 & 51,112 & 914 & 15 & 84 & 7472 \\
\hline & GA-ASA-5 & 129,824 & 110 & 414 & 46,775 & 1010 & 12 & 96 & 10,323 \\
\hline & GA-ASA-6 & 129,813 & 117 & 449 & 51,319 & 898 & 16 & 88 & 7699 \\
\hline & GA-ASA-7 & 130,248 & 119 & 440 & 50,683 & 849 & 13 & 83 & 7516 \\
\hline & GA-ASA-8 & 129,661 & 110 & 428 & 48,115 & 1030. & 11 & 95 & 9821 \\
\hline & GA-ASA-9 & 129,677 & 115 & 456 & 51,859 & 895 & 11 & 92 & 8308 \\
\hline
\end{tabular}

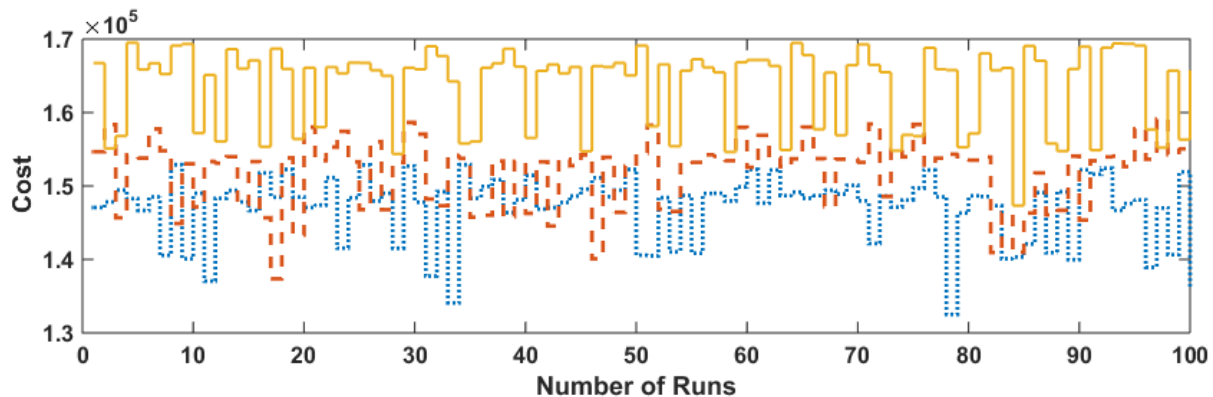

(a) Results of GA-1

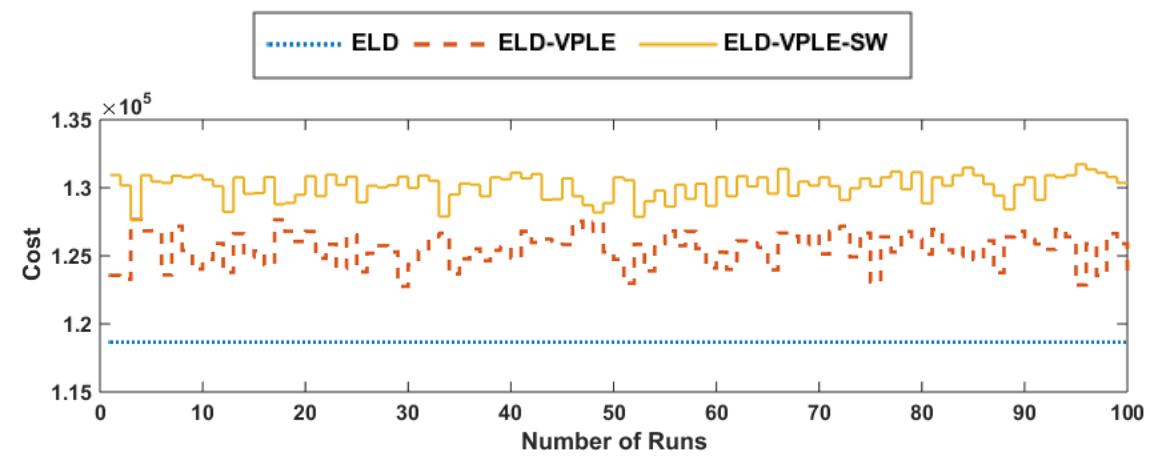

(b) Results of GA-ASA-1

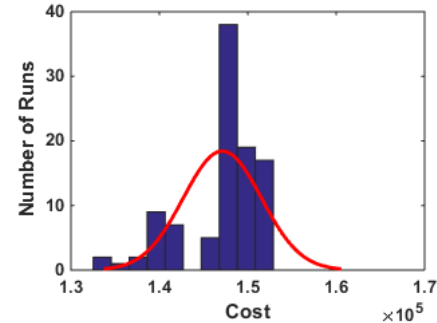

(c) ELD for GA-1

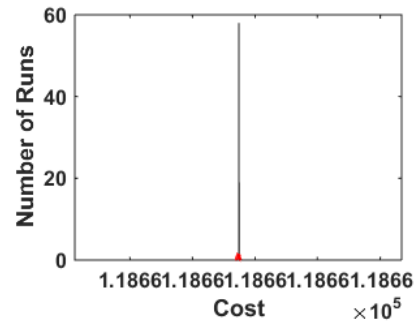

(f) ELD for GA-ASA-1

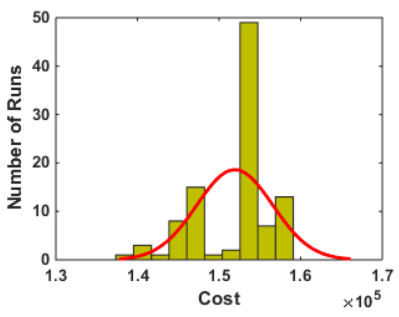

(d) ELD-VPLE for GA-1

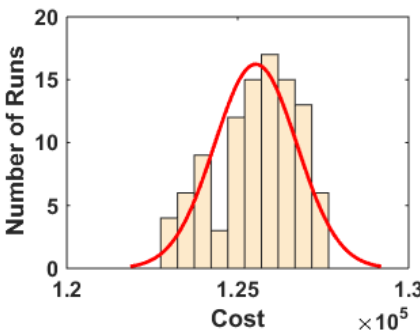

(g) ELD-VPLE for GA-ASA-1

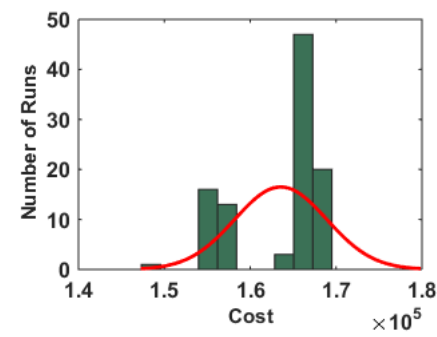

(e) ELD-VPLE-SW for GA-1

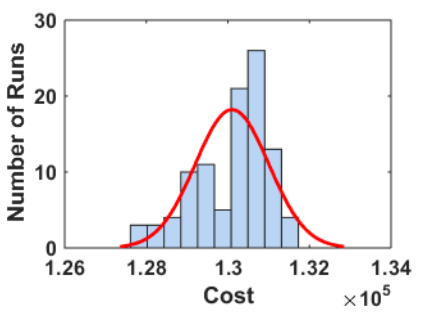

(h) ELD-VPLE-SW for

GA-ASA-1

Figure 3. The comparison of results on the basis of 100 independent runs of GA-1 and GA-ASA-1 for all three load dispatch problems. 


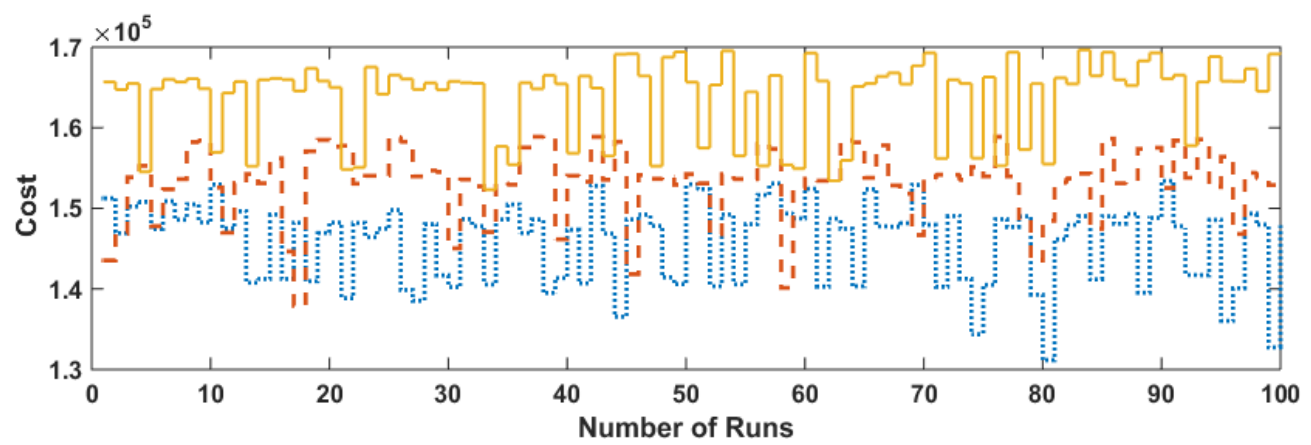

(a) Results of GA-4

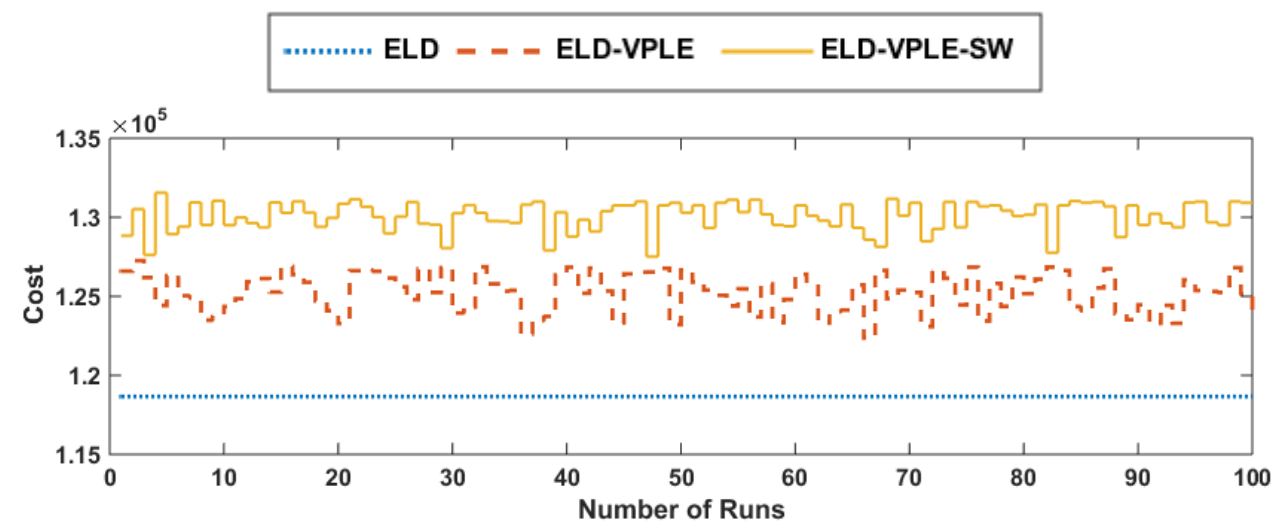

(b) Results of GA-ASA-4

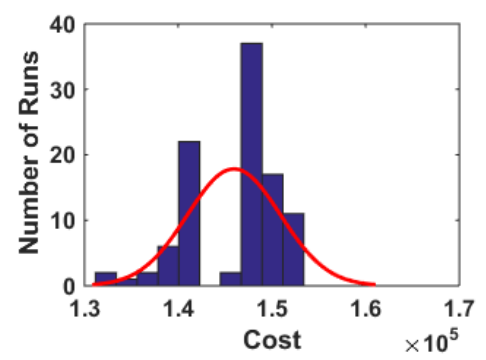

(c) ELD for GA-4

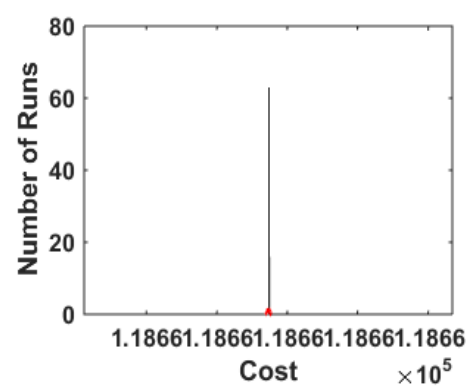

(f) ELD for GA-ASA-4

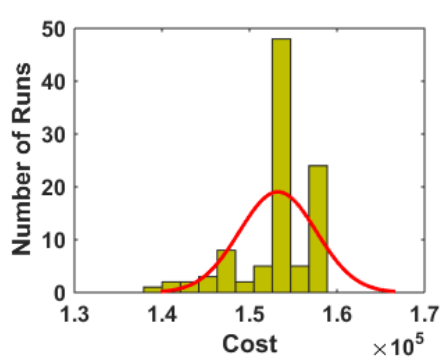

(d) ELD-VPLE for GA-4

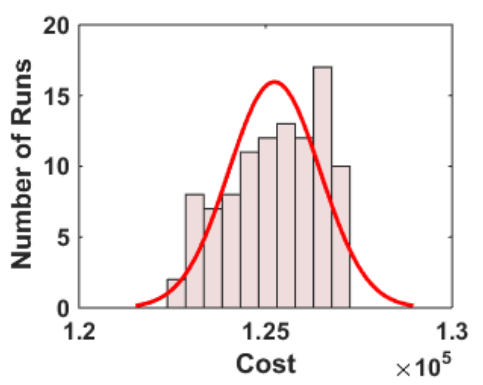

(g) ELD-VPLE for GA-ASA-4

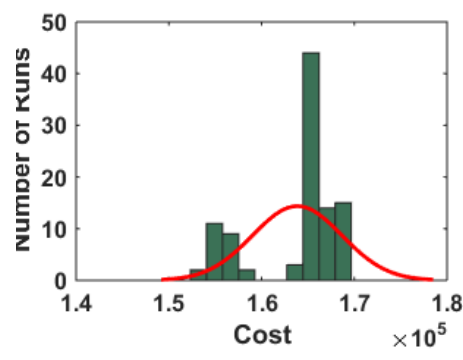

(e) ELD-VPLE-SW for GA-4

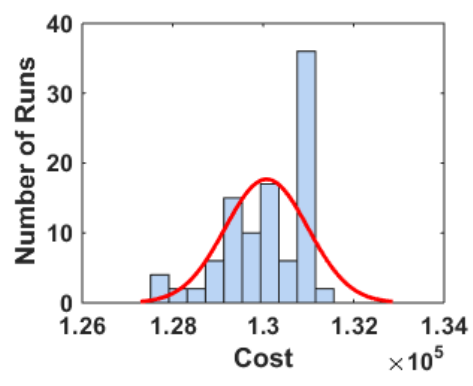

(h) ELD-VPLE-SW for

GA-ASA-4

Figure 4. The comparison of results on the basis of 100 independent runs of GA-4 and GA-ASA-4 for all three load dispatch problems. 


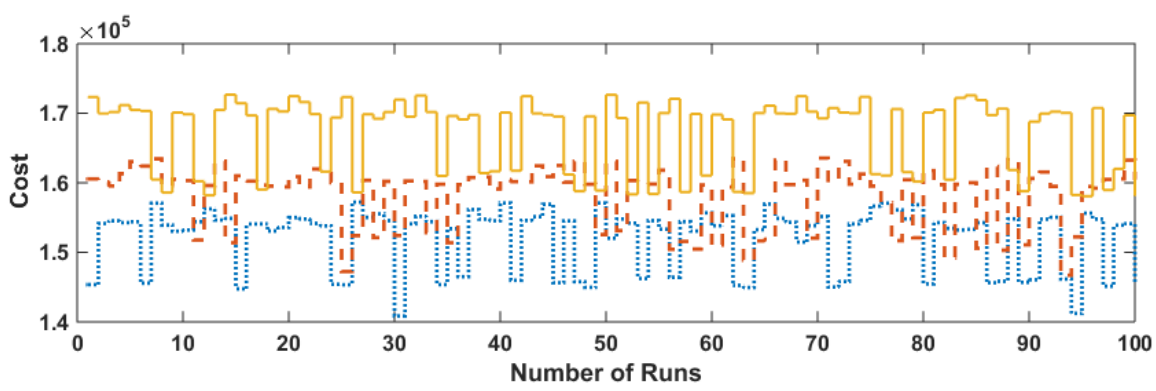

(a) Results of GA-8

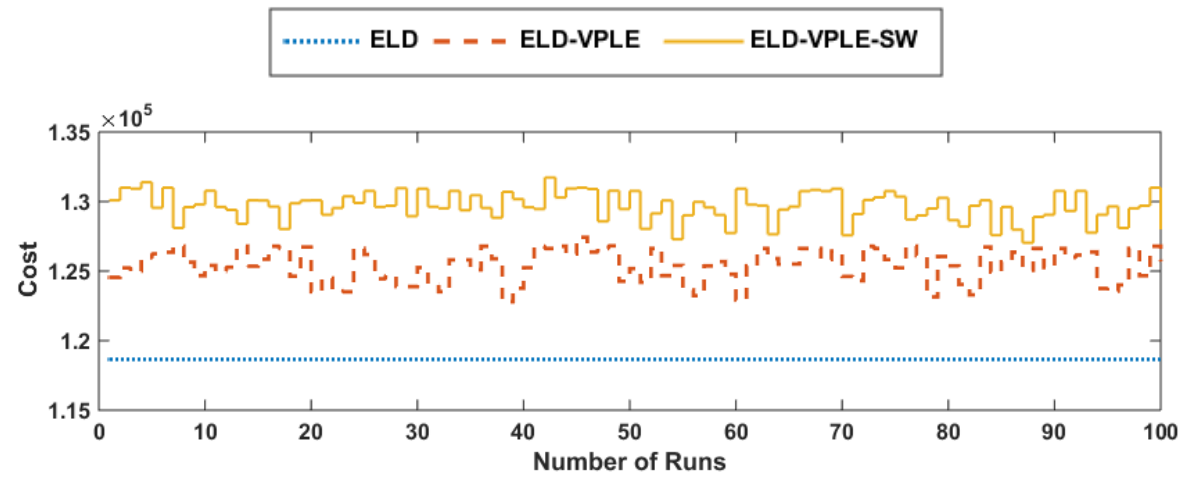

(b) Results of GA-ASA-8

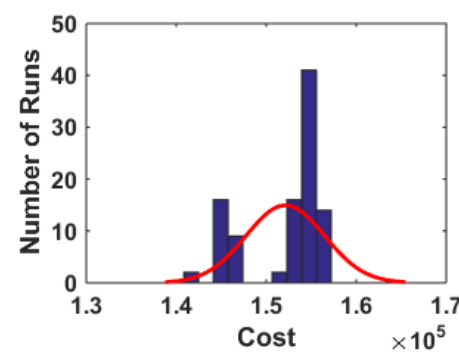

(c) ELD for GA-8

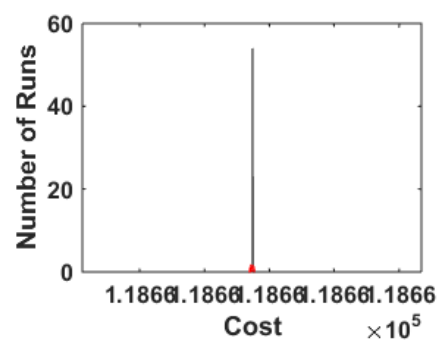

(f) ELD for GA-ASA-8

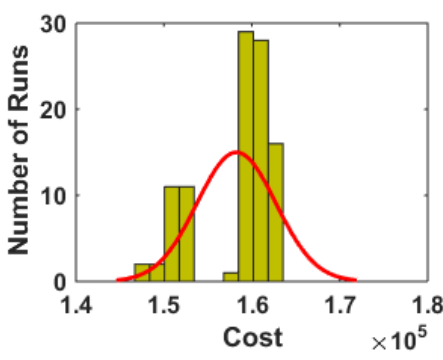

(d) ELD-VPLE for GA-8

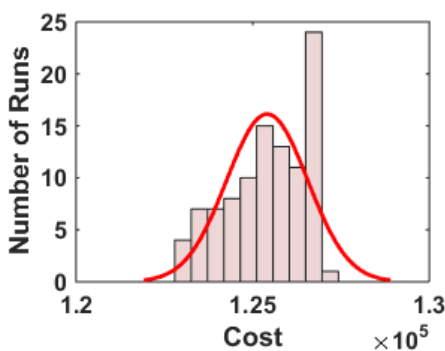

(g) ELD-VPLE for GA-ASA-8

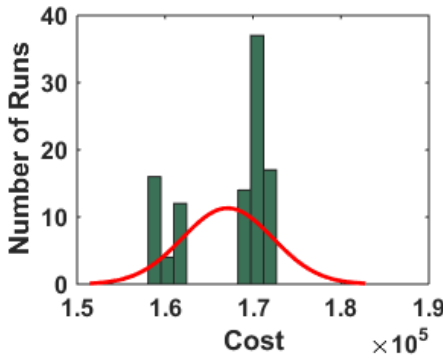

(e) ELD-VPLE-SW for GA-8

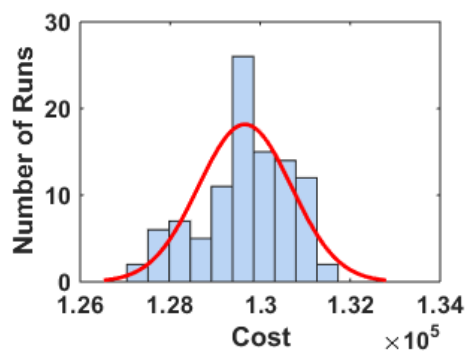

(h) ELD-VPLE-SW for GA-ASA-8

Figure 5. The comparison of results on the basis of 100 independent runs of GA-8 and GA-ASA-8 for all three load dispatch problems.

\section{Conclusions}

The conclusions are summarized as follows:

- Bio-inspired computational heuristics is exploited for solving effectively the integrated power plants systems based on thermal and wind generating units. The proposed BCHAs were based on nine variants of GAs and were designed by using different sets of reproduction operators and each global search method was aided with ASA for rapid local convergence. 
- The performance of proposed schemes was examined for solving ELD, ELD-VPLE, ELD-VPLE-SW problems based on 40 generating units with a fix load demand of 10,500 MW. It was found that all nine integrated approaches were viable solvers with reasonable accuracy. Additionally, sequential computing schemes gave relatively better results than standalone approaches.

- Regarding the smooth cost function based ELD problem, there was no difference in the performance for each integrated methodology, while in the variants of Gas, the best cost was achieved using GA-4, i.e., $131,173.36 \$ / \mathrm{hr}$, while in case of GA-ASA, the best minimum cost was achieved through GA-9, i.e., $118,600 \$ / \mathrm{hr}$.

- Regarding the non-convex cost function based ELD-VPLE problem, the minimum cost was achieved using GA-ASA-1, i.e., 137,359\$/hr., while the results of combined optimization approaches were relatively better than GA variants. However the best minimum cost was achieved by standalone GA-6 is $122,175 \$ / \mathrm{hr}$.

- The scenario of the integrated power plant system was represented with ELD-VPLE-SW. The most effective optimization solver was GA-1 in terms of accuracy and convergence for the standalone scheme, while for sequential computing schemes, the results of GA-ASA-8 were found to be superior.

- The validation and verification for the performance of each optimization solver was established from 100 independent trails to solve all three load dispatch problems by using the detailed analysis through statistical operators, convergence curves, as well as, histogram illustrations.

Some potential research directions are briefly narrated as:

- The presented nine variant of GAs aided ASA, can be a good alternative to be explored or exploited in future for the unit commitment problem in the energy sector.

- The application of proposed optimization algorithms can be explored for a variety of integrated load dispatch problems based on wind, solar, hydel, and biomass, generating units for dynamic and static requirements.

- The newly introduced optimization solvers, including fractional order partial swarm optimization algorithms, fireworks algorithms, moth-flame algorithms, backtracking search optimization algorithms and differential search optimization algorithms can give quality solutions for problems arising in integrated power plant systems.

Author Contributions: R.J. provided data, designed the analytical approach proposed and wrote the paper; B.M. conceived the research theme, and N.H.K. and M.A.Z.R. performed analysis.

Acknowledgments: This work was supported by the Famous Teachers Cultivation planning for Teaching of North China Electric Power University (the Fourth Period).

Conflicts of Interest: The authors have no conflicts of interest to declare.

\section{Appendix A}

The parameters of thermal 40GUs based load dispatch systems are provided in Table A1.

Table A1. The parameters of 40GUs system based ELD problems.

\begin{tabular}{cccccccc}
\hline Generator & Pmin (MW) & Pmax (MW) & $\boldsymbol{a}$ & $\boldsymbol{b}$ & $\boldsymbol{c}$ & $\boldsymbol{e}$ & $\boldsymbol{f}$ \\
\hline 1 & 36 & 114 & 0.00690 & 6.73 & 94.705 & 100 & 0.084 \\
2 & 36 & 114 & 0.00690 & 6.73 & 94.705 & 100 & 0.084 \\
3 & 60 & 120 & 0.02028 & 7.07 & 309.54 & 100 & 0.084 \\
4 & 80 & 190 & 0.00942 & 8.18 & 369.03 & 150 & 0.063 \\
5 & 47 & 97 & 0.0114 & 5.35 & 148.89 & 120 & 0.077 \\
6 & 68 & 140 & 0.01142 & 8.05 & 222.33 & 100 & 0.084 \\
\hline
\end{tabular}


Table A1. Cont.

\begin{tabular}{cccccccc}
\hline Generator & Pmin $(\mathbf{M W})$ & Pmax (MW) & $\boldsymbol{a}$ & $\boldsymbol{b}$ & $\boldsymbol{c}$ & $\boldsymbol{e}$ & $\boldsymbol{f}$ \\
\hline 7 & 110 & 300 & 0.00357 & 8.03 & 287.71 & 200 & 0.042 \\
8 & 135 & 300 & 0.00492 & 6.99 & 391.98 & 200 & 0.042 \\
9 & 135 & 300 & 0.00573 & 6.60 & 455.76 & 200 & 0.042 \\
10 & 130 & 300 & 0.00605 & 12.9 & 722.82 & 200 & 0.042 \\
11 & 94 & 375 & 0.00515 & 12.9 & 635.20 & 200 & 0.042 \\
12 & 94 & 375 & 0.00569 & 12.8 & 654.69 & 200 & 0.042 \\
13 & 125 & 500 & 0.00421 & 12.5 & 913.40 & 300 & 0.035 \\
14 & 125 & 500 & 0.00752 & 8.84 & 1760.4 & 300 & 0.035 \\
15 & 125 & 500 & 0.00708 & 9.15 & 1728.3 & 300 & 0.035 \\
16 & 125 & 500 & 0.00708 & 9.15 & 1728.3 & 300 & 0.035 \\
17 & 220 & 500 & 0.00313 & 7.97 & 647.85 & 300 & 0.035 \\
18 & 220 & 500 & 0.00313 & 7.95 & 649.69 & 300 & 0.035 \\
19 & 242 & 550 & 0.00313 & 7.97 & 647.83 & 300 & 0.035 \\
20 & 242 & 550 & 0.00313 & 7.97 & 647.81 & 300 & 0.035 \\
21 & 254 & 550 & 0.00298 & 6.63 & 785.96 & 300 & 0.035 \\
22 & 254 & 550 & 0.00298 & 6.63 & 785.96 & 300 & 0.035 \\
23 & 254 & 550 & 0.00248 & 6.66 & 794.53 & 300 & 0.035 \\
24 & 254 & 550 & 0.00248 & 6.66 & 794.53 & 300 & 0.035 \\
25 & 254 & 550 & 0.00277 & 7.10 & 801.32 & 300 & 0.035 \\
26 & 254 & 550 & 0.00277 & 7.10 & 801.32 & 300 & 0.035 \\
27 & 10 & 150 & 0.52124 & 3.33 & 1055.1 & 120 & 0.077 \\
28 & 10 & 150 & 0.52124 & 3.33 & 1055.1 & 120 & 0.077 \\
29 & 10 & 150 & 0.52124 & 3.33 & 1055.1 & 120 & 0.077 \\
30 & 47 & 97 & 0.01140 & 5.35 & 148.89 & 120 & 0.077 \\
31 & 60 & 190 & 0.00160 & 6.43 & 222.92 & 150 & 0.063 \\
32 & 60 & 190 & 0.00160 & 6.43 & 222.92 & 150 & 0.063 \\
33 & 60 & 190 & 0.00160 & 6.43 & 222.92 & 150 & 0.063 \\
34 & 90 & 200 & 0.0001 & 8.95 & 107.87 & 200 & 0.042 \\
35 & 90 & 200 & 0.0001 & 8.62 & 116.58 & 200 & 0.042 \\
36 & 90 & 200 & 0.0001 & 8.62 & 116.58 & 200 & 0.042 \\
37 & 25 & 110 & 0.0161 & 5.88 & 307.45 & 80 & 0.098 \\
38 & 25 & 110 & 0.0161 & 5.88 & 307.45 & 80 & 0.098 \\
39 & 25 & 110 & 0.0161 & 5.88 & 307.45 & 80 & 0.098 \\
40 & 242 & 550 & 0.00313 & 7.97 & 647.83 & 300 & 0.035 \\
\hline & & & & & & &
\end{tabular}

\section{Appendix B}

The parameters of wind based generating units are provided in Table A2.

Table A2. The parameters of wind based generating units.

\begin{tabular}{ccccccccc}
\hline $\mathrm{C}_{\mathbf{1}}$ & $\mathrm{C}_{\mathbf{2}}$ & $\mathrm{C}_{\mathbf{3}}$ & $\mathbf{K}_{\mathbf{1}}$ & $\mathbf{K}_{\mathbf{2}}$ & $\mathbf{K}_{\mathbf{3}}$ & $\mathbf{D}_{\mathbf{1}}$ & $\mathbf{D}_{\mathbf{2}}$ & $\mathbf{D}_{\mathbf{3}}$ \\
\hline 8 & 7 & 6 & 2 & 2.4 & 1.7 & 120 & 120 & 120 \\
$\mathrm{~V}_{1(\mathrm{~m} / \mathrm{s})}$ & $\mathrm{V}_{\mathrm{in}(\mathrm{m} / \mathrm{s})}$ & $\mathrm{V}_{\mathrm{out}(\mathrm{m} / \mathrm{s})}$ & $\mathrm{C}_{\mathrm{rw} 1(\mathrm{MWh})}$ & $\mathrm{C}_{\mathrm{rw} 2(\mathrm{MWh})}$ & $\mathrm{C}_{\mathrm{rw} 3(\mathrm{MWh})}$ & $\mathrm{C}_{\mathrm{rp} 1(\mathrm{MWh})}$ & $\mathrm{C}_{\mathrm{rp} 2(\mathrm{MWh})}$ & $\mathrm{C}_{\mathrm{rp} 3(\mathrm{MWh})}$ \\
14 & 4 & 25 & 30 & 30 & 30 & 30 & 30 & 30 \\
\hline
\end{tabular}

\section{Appendix C}

The results in terms of power output of GA and GA-ASA for ELD, ELD-VPLE and ELD-VPLE-SW problems are provided in Tables A3-A5, respectively. 
Table A3. The results in terms of power output of GA and GA-ASA for ELD problems based on 40 GUs without considering VPLE.

\begin{tabular}{|c|c|c|c|c|c|c|c|c|c|c|c|c|c|c|c|c|c|c|}
\hline \multirow{2}{*}{ GU } & \multicolumn{9}{|c|}{ Variants of GA } & \multicolumn{9}{|c|}{ Variants of GA-ASA } \\
\hline & 1 & 2 & 3 & 4 & 5 & 6 & 7 & 8 & 9 & 1 & 2 & 3 & 4 & 5 & 6 & 7 & 8 & 9 \\
\hline $\mathrm{P}_{1}$ & 104.26 & 110.42 & 109.93 & 108.01 & 110.53 & 109.02 & 113.23 & 110.54 & 110.81 & 114.00 & 114.00 & 114.00 & 114.00 & 114.00 & 114.00 & 114.00 & 114.00 & 114.00 \\
\hline $\mathrm{P}_{2}$ & 113.01 & 110.42 & 110.03 & 102.85 & 110.23 & 110.64 & 106.01 & 110.66 & 110.87 & 114.00 & 114.00 & 114.00 & 114.00 & 114.00 & 114.00 & 114.00 & 114.00 & 114.00 \\
\hline $\mathrm{P}_{3}$ & 114.99 & 116.41 & 115.98 & 104.70 & 116.29 & 114.98 & 114.29 & 116.15 & 115.69 & 120.00 & 120.00 & 120.00 & 120.00 & 120.00 & 120.00 & 120.00 & 120.00 & 120.00 \\
\hline $\mathrm{P}_{4}$ & 182.22 & 186.42 & 186.97 & 172.97 & 186.67 & 185.92 & 179.14 & 186.66 & 186.25 & 190.00 & 190.00 & 190.00 & 190.00 & 190.00 & 190.00 & 190.00 & 190.00 & 190.00 \\
\hline $\mathrm{P}_{5}$ & 89.13 & 94.42 & 93.97 & 87.16 & 93.39 & 94.72 & 93.05 & 93.66 & 93.41 & 97.00 & 97.00 & 97.00 & 97.00 & 97.00 & 97.00 & 97.00 & 97.00 & 97.00 \\
\hline $\mathrm{P}_{6}$ & 135.77 & 136.42 & 135.95 & 133.55 & 136.23 & 134.90 & 134.15 & 137.15 & 136.72 & 140.00 & 140.00 & 140.00 & 140.00 & 140.00 & 140.00 & 140.00 & 140.00 & 140.00 \\
\hline $\mathrm{P}_{7}$ & 294.78 & 296.42 & 295.95 & 299.36 & 296.24 & 296.90 & 294.66 & 296.17 & 294.29 & 300.00 & 300.00 & 300.00 & 300.00 & 300.00 & 300.00 & 300.00 & 300.00 & 300.00 \\
\hline $\mathrm{P}_{8}$ & 291.76 & 296.42 & 296.02 & 283.74 & 296.45 & 296.86 & 297.37 & 296.66 & 294.97 & 300.00 & 300.00 & 300.00 & 300.00 & 300.00 & 300.00 & 300.00 & 300.00 & 300.00 \\
\hline P9 & 288.03 & 296.42 & 295.96 & 289.37 & 296.33 & 297.55 & 295.84 & 297.65 & 295.87 & 300.00 & 300.00 & 300.00 & 300.00 & 300.00 & 300.00 & 300.00 & 300.00 & 300.00 \\
\hline$P_{10}$ & 296.96 & 296.42 & 295.89 & 290.86 & 296.96 & 295.76 & 292.06 & 296.63 & 296.84 & 130.00 & 130.00 & 130.00 & 130.00 & 130.00 & 130.00 & 130.00 & 130.00 & 130.00 \\
\hline $\mathrm{P}_{11}$ & 373.38 & 371.42 & 371.85 & 356.12 & 371.22 & 370.86 & 374.90 & 371.64 & 370.71 & 94.00 & 94.00 & 94.00 & 94.00 & 94.00 & 94.00 & 94.00 & 94.00 & 94.00 \\
\hline$P_{12}$ & 370.31 & 371.34 & 370.99 & 349.42 & 371.08 & 370.25 & 370.45 & 371.66 & 370.55 & 94.00 & 94.00 & 94.00 & 94.00 & 94.00 & 94.00 & 94.00 & 94.00 & 94.00 \\
\hline $\mathrm{P}_{13}$ & 378.98 & 379.80 & 380.47 & 370.85 & 414.06 & 379.75 & 491.18 & 378.19 & 379.83 & 125.00 & 125.00 & 125.00 & 125.00 & 125.00 & 125.00 & 125.00 & 125.00 & 125.00 \\
\hline $\mathrm{P}_{14}$ & 394.11 & 377.49 & 379.90 & 376.44 & 382.13 & 385.65 & 376.03 & 380.76 & 380.08 & 271.67 & 271.67 & 271.67 & 271.67 & 271.67 & 271.67 & 271.67 & 271.67 & 271.67 \\
\hline $\mathrm{P}_{15}$ & 379.10 & 378.53 & 378.85 & 452.45 & 414.08 & 392.10 & 380.98 & 377.65 & 381.58 & 266.66 & 266.66 & 266.66 & 266.66 & 266.66 & 266.66 & 266.66 & 266.66 & 266.66 \\
\hline $\mathrm{P}_{16}$ & 499.11 & 378.31 & 378.30 & 372.42 & 380.44 & 381.36 & 367.90 & 381.11 & 377.84 & 266.66 & 266.66 & 266.66 & 266.66 & 266.66 & 266.66 & 266.66 & 266.66 & 266.66 \\
\hline $\mathrm{P}_{17}$ & 294.15 & 379.64 & 379.34 & 395.28 & 418.37 & 380.64 & 376.86 & 377.86 & 379.01 & 500.00 & 500.00 & 500.00 & 500.00 & 500.00 & 500.00 & 500.00 & 500.00 & 500.00 \\
\hline $\mathrm{P}_{18}$ & 374.92 & 378.35 & 378.34 & 378.94 & 416.93 & 377.17 & 491.13 & 437.12 & 377.14 & 500.00 & 500.00 & 500.00 & 500.00 & 500.00 & 500.00 & 500.00 & 500.00 & 500.00 \\
\hline $\mathrm{P}_{19}$ & 381.67 & 445.45 & 380.76 & 429.41 & 427.37 & 444.50 & 316.51 & 380.84 & 449.02 & 550.00 & 550.00 & 550.00 & 550.00 & 550.00 & 550.00 & 550.00 & 550.00 & 550.00 \\
\hline $\mathrm{P}_{20}$ & 374.44 & 378.68 & 445.85 & 366.75 & 381.05 & 378.64 & 503.95 & 437.49 & 381.23 & 550.00 & 550.00 & 550.00 & 550.00 & 550.00 & 550.00 & 550.00 & 550.00 & 550.00 \\
\hline$P_{21}$ & 367.83 & 515.23 & 379.20 & 349.20 & 380.51 & 380.31 & 380.01 & 379.08 & 446.48 & 550.00 & 550.00 & 550.00 & 550.00 & 550.00 & 550.00 & 550.00 & 550.00 & 550.00 \\
\hline$P_{22}$ & 376.98 & 376.63 & 378.23 & 535.04 & 379.94 & 432.77 & 406.31 & 379.67 & 449.04 & 550.00 & 550.00 & 550.00 & 550.00 & 550.00 & 550.00 & 550.00 & 550.00 & 550.00 \\
\hline $\mathrm{P}_{23}$ & 519.05 & 377.96 & 379.48 & 449.96 & 430.43 & 444.34 & 383.32 & 450.25 & 381.14 & 550.00 & 550.00 & 550.00 & 550.00 & 550.00 & 550.00 & 550.00 & 550.00 & 550.00 \\
\hline $\mathrm{P}_{24}$ & 388.12 & 379.74 & 377.68 & 502.64 & 381.12 & 376.41 & 380.99 & 375.94 & 379.48 & 550.00 & 550.00 & 550.00 & 550.00 & 550.00 & 550.00 & 550.00 & 550.00 & 550.00 \\
\hline $\mathrm{P}_{25}$ & 529.89 & 380.76 & 475.00 & 368.14 & 381.47 & 448.18 & 505.01 & 377.16 & 378.60 & 550.00 & 550.00 & 550.00 & 550.00 & 550.00 & 550.00 & 550.00 & 550.00 & 550.00 \\
\hline $\mathrm{P}_{26}$ & 382.01 & 378.46 & 417.66 & 453.88 & 378.51 & 378.40 & 377.79 & 450.54 & 379.88 & 550.00 & 550.00 & 550.00 & 550.00 & 550.00 & 550.00 & 550.00 & 550.00 & 550.00 \\
\hline $\mathrm{P}_{27}$ & 10.01 & 79.50 & 143.97 & 114.37 & 97.17 & 128.76 & 14.61 & 144.62 & 143.15 & 10.00 & 10.00 & 10.00 & 10.00 & 10.00 & 10.00 & 10.00 & 10.00 & 10.00 \\
\hline $\mathrm{P}_{28}$ & 21.09 & 146.39 & 48.51 & 11.21 & 110.67 & 74.47 & 127.51 & 87.89 & 73.80 & & 10.00 & 10.00 & 10.00 & 10.00 & 10.00 & 10.00 & 10.00 & 10.00 \\
\hline $\mathrm{P}_{29}$ & 120.05 & 76.74 & 75.45 & 28.08 & 102.95 & 89.60 & 15.81 & 75.96 & 78.32 & 10.00 & 10.00 & 10.00 & 10.00 & 10.00 & 10.00 & 10.00 & 10.00 & 10.00 \\
\hline $\mathrm{P}_{30}$ & 86.79 & 94.98 & 94.04 & 90.70 & 93.26 & 92.92 & 96.80 & 94.49 & 94.46 & 97.00 & 97.00 & 97.00 & 97.00 & 97.00 & 97.00 & 97.00 & 97.00 & 97.00 \\
\hline $\mathrm{P}_{31}$ & 186.80 & 186.42 & 188.00 & 188.65 & 186.51 & 187.59 & 184.68 & 186.73 & 187.78 & 190.00 & 190.00 & 190.00 & 190.00 & 190.00 & 190.00 & 190.00 & 190.00 & 190.00 \\
\hline $\mathrm{P}_{32}$ & 175.01 & 186.42 & 185.99 & 179.04 & 186.23 & 186.91 & 183.07 & 186.66 & 189.20 & 190.00 & 190.00 & 190.00 & 190.00 & 190.00 & 190.00 & 190.00 & 190.00 & 190.00 \\
\hline$P_{33}$ & 187.29 & 186.42 & 185.87 & 175.25 & 186.25 & 188.94 & 186.93 & 186.14 & 185.98 & 190.00 & 190.00 & 190.00 & 190.00 & 190.00 & 190.00 & 190.00 & 190.00 & 190.00 \\
\hline $\mathrm{P}_{34}$ & 197.19 & 196.42 & 196.80 & 196.60 & 195.81 & 195.89 & 199.86 & 196.66 & 194.86 & 200.00 & 200.00 & 200.00 & 200.00 & 200.00 & 200.00 & 200.00 & 200.00 & 200.00 \\
\hline $\mathrm{P}_{35}$ & 197.10 & 196.42 & 196.76 & 194.61 & 196.33 & 196.92 & 199.78 & 196.67 & 195.87 & 200.00 & 200.00 & 200.00 & 200.00 & 200.00 & 200.00 & 200.00 & 200.00 & 200.00 \\
\hline $\mathrm{P}_{36}$ & 193.26 & 196.42 & 195.49 & 179.11 & 197.33 & 196.94 & 195.15 & 196.66 & 195.86 & 200.00 & 200.00 & 200.00 & 200.00 & 200.00 & 200.00 & 200.00 & 200.00 & 200.00 \\
\hline $\mathrm{P}_{37}$ & 105.68 & 106.42 & 105.80 & 101.07 & 106.31 & 106.57 & 97.64 & 106.66 & 106.79 & 110.00 & 110.00 & 110.00 & 110.00 & 110.00 & 110.00 & 110.00 & 110.00 & 110.00 \\
\hline $\mathrm{P}_{38}$ & 103.10 & 106.42 & 107.02 & 90.17 & 106.26 & 105.98 & 106.18 & 105.83 & & & 110.00 & & & 110.00 & 110.00 & 110.00 & 110.00 & 110.00 \\
\hline $\mathrm{P}_{39}$ & 104.43 & 106.42 & 106.98 & 105.93 & 105.94 & 108.10 & 108.87 & 107.21 & 104.33 & 110.00 & 110.00 & 110.00 & 110.00 & 110.00 & 110.00 & 110.00 & 110.00 & 110.00 \\
\hline $\mathrm{P}_{40}$ & 517.24 & 446.64 & 480.78 & 465.74 & 380.93 & 381.84 & 379.97 & 378.92 & 446.55 & 550.00 & 550.00 & 550.00 & 550.00 & 550.00 & 550.00 & 550.00 & 550.00 & 550.00 \\
\hline
\end{tabular}


Table A4. The results in terms of power output of GA and GA-ASA for ELD problem based on 40 Gus by considering VPLE.

\begin{tabular}{|c|c|c|c|c|c|c|c|c|c|c|c|c|c|c|c|c|c|c|}
\hline \multirow{2}{*}{ GU } & \multicolumn{9}{|c|}{ Variants of GA } & \multicolumn{9}{|c|}{ Variants of GA-ASA } \\
\hline & 1 & 2 & 3 & 4 & 5 & 6 & 7 & 8 & 9 & 1 & 2 & 3 & 4 & 5 & 6 & 7 & 8 & 9 \\
\hline $\mathrm{P}_{1}$ & 113.68 & 110.41 & 109.95 & 110.18 & 111.49 & 110.60 & 111.47 & 109.49 & 111.34 & 110.80 & 111.64 & 110.80 & 110.80 & 110.80 & 110.80 & 110.80 & 114.00 & 114.00 \\
\hline $\mathrm{P}_{2}$ & 105.05 & 110.07 & 110.21 & 106.60 & 110.49 & 111.02 & 109.68 & 111.47 & 110.69 & 74.74 & 111.45 & 110.80 & 110.80 & 110.86 & 110.80 & 110.80 & 114.00 & 114.00 \\
\hline $\mathrm{P}_{3}$ & 112.96 & 115.87 & 115.90 & 115.51 & 115.49 & 117.03 & 119.81 & 115.34 & 117.14 & 97.40 & 97.40 & 120.00 & 97.40 & 120.00 & 120.00 & 97.40 & 97.40 & 120.00 \\
\hline $\mathrm{P}_{4}$ & 182.90 & 186.20 & 185.98 & 184.74 & 186.46 & 185.98 & 188.15 & 186.40 & 185.10 & 80.00 & 179.73 & 179.73 & 179.73 & 179.73 & 129.87 & 129.87 & 129.87 & 129.87 \\
\hline $\mathrm{P}_{5}$ & 87.36 & 93.85 & 93.01 & 88.74 & 93.49 & 92.04 & 93.99 & 93.25 & 93.03 & 87.80 & 97.00 & 93.97 & 87.80 & 88.02 & 97.00 & 97.00 & 89.61 & 97.00 \\
\hline $\mathrm{P}_{6}$ & 135.91 & 138.09 & 137.27 & 139.70 & 138.91 & 136.06 & 137.76 & 137.38 & 137.34 & 140.00 & 140.00 & 140.00 & 140.00 & 140.00 & 140.00 & 140.00 & 140.00 & 140.00 \\
\hline $\mathrm{P}_{7}$ & 297.86 & 296.63 & 297.22 & 291.51 & 296.49 & 295.97 & 295.16 & 297.48 & 297.27 & 300.00 & 259.60 & 300.00 & 300.00 & 300.00 & 259.60 & 259.60 & 259.60 & 300.00 \\
\hline $\mathrm{P}_{8}$ & 286.46 & 296.11 & 296.23 & 293.08 & 296.95 & 296.95 & 299.72 & 296.44 & 296.18 & 284.60 & 284.60 & 284.60 & 284.60 & 284.60 & 284.60 & 284.60 & 284.60 & 284.60 \\
\hline P9 & 292.44 & 295.94 & 296.09 & 292.58 & 296.49 & 295.00 & 295.54 & 296.43 & 297.21 & 284.60 & 284.60 & 284.60 & 284.60 & 284.60 & 284.60 & 284.60 & 284.60 & 284.60 \\
\hline$P_{10}$ & 294.94 & 296.13 & 297.10 & 292.90 & 296.49 & 295.97 & 299.84 & 297.32 & 295.14 & 130.00 & 130.00 & 130.00 & 130.00 & 204.80 & 130.00 & 130.00 & 130.00 & 130.00 \\
\hline $\mathrm{P}_{11}$ & 371.15 & 371.40 & 370.20 & 360.53 & 371.45 & 371.01 & 370.85 & 371.49 & 371.81 & 318.40 & 243.60 & 243.60 & 318.40 & 318.40 & 243.60 & 168.80 & 318.40 & 243.60 \\
\hline $\mathrm{P}_{12}$ & 371.40 & 371.11 & 372.54 & 367.15 & 371.49 & 371.03 & 371.52 & 372.65 & 370.58 & 318.40 & 168.80 & 318.40 & 318.40 & 318.40 & 168.80 & 243.60 & 243.60 & 168.80 \\
\hline $\mathrm{P}_{13}$ & 399.82 & 376.82 & 384.39 & 374.27 & 380.05 & 380.11 & 396.77 & 433.54 & 378.18 & 214.76 & 394.28 & 304.52 & 214.76 & 125.00 & 394.28 & 394.28 & 304.52 & 394.28 \\
\hline $\mathrm{P}_{14}$ & 481.35 & 432.68 & 381.55 & 391.22 & 378.74 & 381.36 & 383.99 & 423.66 & 378.53 & 304.52 & 484.04 & 214.76 & 214.76 & 214.76 & 304.52 & 394.28 & 304.52 & 304.52 \\
\hline $\mathrm{P}_{15}$ & 386.83 & 385.23 & 378.29 & 388.42 & 380.58 & 376.28 & 363.82 & 377.95 & 379.36 & 304.52 & 304.52 & 214.76 & 125.00 & 214.76 & 304.52 & 394.28 & 394.28 & 304.52 \\
\hline $\mathrm{P}_{16}$ & 372.68 & 381.30 & 379.76 & 382.01 & 377.51 & 378.40 & 385.30 & 400.05 & 377.84 & 304.52 & 304.52 & 394.28 & 304.52 & 214.76 & 304.52 & 394.28 & 394.28 & 304.52 \\
\hline$P_{17}$ & 463.13 & 379.69 & 445.59 & 385.09 & 447.68 & 380.45 & 364.38 & 378.89 & 380.59 & 489.28 & 489.28 & 399.52 & 489.28 & 489.28 & 399.52 & 399.52 & 399.52 & 489.28 \\
\hline $\mathrm{P}_{18}$ & 475.03 & 399.82 & 379.05 & 374.55 & 379.97 & 380.52 & 379.84 & 380.68 & 446.02 & 399.52 & 489.28 & 399.52 & 489.28 & 489.28 & 489.28 & 399.52 & 399.52 & 489.28 \\
\hline $\mathrm{P}_{19}$ & 425.57 & 381.54 & 378.96 & 375.22 & 448.88 & 377.49 & 352.18 & 380.83 & 380.52 & 511.28 & 511.28 & 511.28 & 511.28 & 511.28 & 511.28 & 511.28 & 511.28 & 511.28 \\
\hline $\mathrm{P}_{20}$ & 378.68 & 381.34 & 381.07 & 373.04 & 380.29 & 377.53 & 396.67 & 380.00 & 400.84 & 511.28 & 331.76 & 511.28 & 511.28 & 511.28 & 511.28 & 421.52 & 511.28 & 421.52 \\
\hline$P_{21}$ & 377.41 & 380.08 & 439.15 & 370.32 & 437.23 & 452.26 & 480.10 & 456.86 & 380.07 & 523.28 & 523.28 & 523.28 & 523.28 & 523.28 & 523.28 & 523.28 & 523.28 & 523.28 \\
\hline $\mathrm{P}_{22}$ & 342.65 & 434.14 & 379.78 & 465.87 & 376.55 & 380.39 & 468.39 & 380.57 & 379.76 & 523.28 & 523.28 & 523.28 & 523.28 & 523.28 & 523.28 & 523.28 & 523.28 & 523.28 \\
\hline $\mathrm{P}_{23}$ & 391.60 & 381.49 & 378.17 & 377.86 & 440.41 & 379.27 & 464.56 & 378.00 & 377.77 & 523.28 & 523.28 & 523.28 & 523.28 & 523.28 & 523.28 & 523.28 & 523.28 & 433.52 \\
\hline $\mathrm{P}_{24}$ & 393.98 & 376.72 & 381.54 & 507.85 & 378.21 & 380.59 & 330.46 & 425.23 & 438.45 & 523.28 & 523.28 & 523.28 & 523.28 & 523.28 & 523.28 & 523.28 & 523.28 & 523.28 \\
\hline$P_{25}$ & 368.35 & 425.73 & 379.82 & 548.74 & 378.85 & 515.41 & 397.21 & 382.00 & 433.57 & 523.28 & 523.28 & 523.28 & 523.28 & 523.28 & 523.28 & 523.28 & 523.28 & 523.28 \\
\hline $\mathrm{P}_{26}$ & 461.86 & 449.35 & 438.72 & 465.38 & 379.02 & 443.31 & 376.78 & 377.87 & 433.30 & 523.28 & 523.28 & 523.28 & 523.28 & 523.28 & 523.28 & 523.28 & 523.28 & 523.28 \\
\hline $\mathrm{P}_{27}$ & 49.89 & 73.79 & 144.05 & 30.29 & 87.85 & 145.04 & 133.03 & 97.64 & 144.74 & 10.00 & 10.00 & 10.00 & 10.00 & 10.00 & 10.00 & 10.00 & 10.00 & 10.00 \\
\hline $\mathrm{P}_{28}$ & 65.97 & 145.56 & 83.78 & 10.17 & 145.49 & 71.17 & 41.40 & 91.42 & 83.62 & 10.00 & 10.00 & 10.00 & 10.00 & 10.00 & 10.00 & 10.00 & 10.00 & 10.00 \\
\hline $\mathrm{P}_{29}$ & 89.52 & 92.16 & 78.36 & 125.37 & 74.08 & 80.78 & 28.40 & 122.94 & 76.59 & 10.00 & 10.00 & 10.00 & 10.00 & 10.00 & 10.00 & 10.00 & 10.00 & 10.00 \\
\hline $\mathrm{P}_{30}$ & 94.65 & 94.16 & 92.68 & 90.81 & 93.44 & 93.00 & 90.98 & 93.23 & 92.24 & 87.80 & 97.00 & 87.80 & 96.34 & 88.41 & 90.56 & 97.00 & 89.51 & 97.00 \\
\hline$P_{31}$ & 184.57 & 186.59 & 186.48 & 186.51 & 187.07 & 186.04 & 182.93 & 186.49 & 187.55 & 190.00 & 190.00 & 190.00 & 190.00 & 190.00 & 190.00 & 190.00 & 190.00 & 190.00 \\
\hline $\begin{array}{l}P_{32} \\
P_{1}\end{array}$ & 185.05 & 185.91 & 186.17 & 179.94 & 186.46 & 187.06 & 188.10 & 188.76 & 187.68 & 190.00 & 190.00 & 190.00 & 190.00 & 190.00 & 190.00 & 190.00 & 190.00 & 190.00 \\
\hline $\mathrm{P}_{33}$ & 183.89 & 185.79 & 187.22 & 189.30 & 186.42 & 188.99 & 184.83 & 186.49 & 187.65 & 190.00 & 190.00 & 190.00 & 190.00 & 190.00 & 190.00 & 190.00 & 190.00 & 190.00 \\
\hline $\mathrm{P}_{34}$ & 193.83 & 195.58 & 196.13 & 192.41 & 196.49 & 197.92 & 197.64 & 197.29 & 196.16 & 164.80 & 164.80 & 164.80 & 200.00 & 200.00 & 200.00 & 164.80 & 164.80 & 166.11 \\
\hline $\mathrm{P}_{35}$ & 197.01 & 195.11 & 197.21 & 189.09 & 196.49 & 195.96 & 194.90 & 197.35 & 197.38 & 200.00 & 164.80 & 200.00 & 200.00 & 200.00 & 164.80 & 180.96 & 164.80 & 200.00 \\
\hline $\mathrm{P}_{36}$ & 193.84 & 198.03 & 195.29 & 194.34 & 196.46 & 195.90 & 194.88 & 196.04 & 196.24 & 200.00 & 164.80 & 200.00 & 200.00 & 200.00 & 164.80 & 200.00 & 164.80 & 200.00 \\
\hline $\begin{array}{l}P_{37} \\
\text { nat }\end{array}$ & 105.95 & 107.12 & 105.70 & 96.74 & 106.49 & 105.93 & 103.50 & 106.36 & 106.24 & 110.00 & 110.00 & 110.00 & 110.00 & 110.00 & 110.00 & 110.00 & 110.00 & 110.00 \\
\hline $\mathrm{P}_{38}$ & 102.44 & 105.85 & 106.17 & 109.72 & 108.49 & 107.05 & 104.41 & 109.46 & 109.56 & 110.00 & 110.00 & 110.00 & 110.00 & 110.00 & 110.00 & 110.00 & 110.00 & 110.00 \\
\hline $\mathrm{P}_{39}$ & 101.25 & 106.69 & 106.23 & 108.49 & 106.49 & 106.02 & 108.97 & 106.32 & 105.99 & 110.00 & 110.00 & 110.00 & 110.00 & 110.00 & 110.00 & 110.00 & 110.00 & 110.00 \\
\hline $\mathrm{P}_{40}$ & 381.10 & 379.94 & 446.98 & 373.77 & 378.62 & 377.08 & 512.12 & 378.97 & 380.74 & 511.28 & 421.52 & 511.28 & 511.28 & 511.28 & 511.28 & 421.52 & 421.52 & 511.28 \\
\hline
\end{tabular}


Table A5. Results in terms of power output of GA and GA-ASA for ELD problem based on 40 GUs by considering VPLE-SW.

\begin{tabular}{|c|c|c|c|c|c|c|c|c|c|c|c|c|c|c|c|c|c|c|}
\hline \multirow{2}{*}{ GU } & \multicolumn{9}{|c|}{ Variants of GA } & \multicolumn{9}{|c|}{ Variants of GA-ASA } \\
\hline & 1 & 2 & 3 & 4 & 5 & 6 & 7 & 8 & 9 & 1 & 2 & 3 & 4 & 5 & 6 & 7 & 8 & 9 \\
\hline $\mathrm{P}_{1}$ & 110.26 & 110.45 & 110.13 & 112.61 & 110.43 & 111.72 & 112.49 & 109.63 & 110.34 & 110.80 & 114.00 & 111.45 & 110.80 & 110.80 & 110.80 & 110.80 & 110.80 & 114.00 \\
\hline $\mathrm{P}_{2}$ & 111.49 & 110.48 & 110.74 & 110.31 & 110.47 & 110.35 & 110.30 & 110.00 & 110.56 & 110.80 & 114.00 & 113.19 & 110.80 & 110.80 & 110.80 & 110.80 & 110.80 & 114.00 \\
\hline $\mathrm{P}_{3}$ & 109.77 & 116.48 & 116.09 & 119.48 & 116.43 & 116.42 & 113.09 & 116.19 & 116.56 & 97.40 & 120.00 & 60.00 & 97.40 & 120.00 & 97.40 & 60.00 & 97.40 & 120.00 \\
\hline $\mathrm{P}_{4}$ & 182.09 & 186.48 & 185.16 & 188.68 & 186.41 & 186.35 & 184.80 & 185.85 & 185.01 & 179.73 & 179.73 & 183.85 & 179.73 & 179.73 & 179.73 & 179.73 & 179.73 & 179.73 \\
\hline $\mathrm{P}_{5}$ & 91.58 & 93.48 & 92.90 & 91.34 & 91.43 & 92.81 & 87.76 & 92.92 & 92.06 & 91.85 & 97.00 & 87.81 & 96.34 & 87.80 & 87.80 & 87.80 & 87.80 & 97.00 \\
\hline $\mathrm{P}_{6}$ & 136.59 & 136.48 & 136.13 & 137.04 & 136.43 & 135.42 & 131.93 & 135.94 & 136.12 & 140.00 & 140.00 & 140.00 & 140.00 & 140.00 & 140.00 & 140.00 & 140.00 & 140.00 \\
\hline $\mathrm{P}_{7}$ & 298.14 & 297.48 & 295.99 & 295.65 & 296.38 & 296.29 & 292.16 & 295.66 & 295.97 & 259.60 & 300.00 & 300.00 & 300.00 & 300.00 & 300.00 & 259.60 & 300.00 & 300.00 \\
\hline $\mathrm{P}_{8}$ & 288.10 & 296.48 & 296.76 & 298.96 & 296.43 & 296.29 & 296.05 & 296.90 & 295.93 & 284.60 & 300.00 & 210.03 & 284.60 & 284.60 & 284.60 & 284.60 & 284.60 & 300.00 \\
\hline P9 & 289.65 & 296.42 & 296.56 & 299.71 & 296.43 & 296.92 & 297.07 & 295.93 & 295.02 & 284.60 & 290.17 & 284.63 & 284.60 & 284.60 & 284.60 & 284.60 & 284.60 & 300.00 \\
\hline$P_{10}$ & 291.58 & 296.48 & 294.19 & 297.20 & 296.43 & 296.26 & 292.12 & 296.07 & 293.97 & 204.80 & 130.00 & 130.00 & 279.60 & 130.00 & 130.00 & 204.58 & 130.00 & 204.80 \\
\hline $\mathrm{P}_{11}$ & 372.69 & 371.48 & 371.83 & 373.94 & 372.43 & 372.51 & 374.94 & 370.92 & 370.94 & 168.80 & 318.40 & 318.36 & 168.80 & 318.40 & 243.60 & 242.76 & 318.40 & 318.40 \\
\hline$P_{12}$ & 368.51 & 371.48 & 370.93 & 372.39 & 371.37 & 371.17 & 370.26 & 370.81 & 371.01 & 168.80 & 168.80 & 168.94 & 318.40 & 318.40 & 168.80 & 242.17 & 318.40 & 168.80 \\
\hline $\mathrm{P}_{13}$ & 375.69 & 378.37 & 378.04 & 381.17 & 376.59 & 377.61 & 383.10 & 378.37 & 379.48 & 304.52 & 304.52 & 304.50 & 304.52 & 304.52 & 304.52 & 394.28 & 214.76 & 214.76 \\
\hline $\mathrm{P}_{14}$ & 372.98 & 380.93 & 379.57 & 380.50 & 381.71 & 382.50 & 373.85 & 377.10 & 380.83 & 394.28 & 394.28 & 394.30 & 214.76 & 214.76 & 394.28 & 304.52 & 304.52 & 304.52 \\
\hline $\mathrm{P}_{15}$ & 373.65 & 379.99 & 380.66 & 420.85 & 377.97 & 383.71 & 371.95 & 379.83 & 379.56 & 394.28 & 394.28 & 394.28 & 394.28 & 214.76 & 394.28 & 394.28 & 304.52 & 304.52 \\
\hline $\mathrm{P}_{16}$ & 497.71 & 377.12 & 378.40 & 382.99 & 378.03 & 376.40 & 382.64 & 379.61 & 380.65 & 484.04 & 304.52 & 214.76 & 304.52 & 214.76 & 394.28 & 394.28 & 304.52 & 394.28 \\
\hline $\mathrm{P}_{17}$ & 377.78 & 378.04 & 380.58 & 375.72 & 379.20 & 380.95 & 388.07 & 378.30 & 381.69 & 489.28 & 399.52 & 399.50 & 399.52 & 489.28 & 399.52 & 399.52 & 399.52 & 399.52 \\
\hline $\mathrm{P}_{18}$ & 385.98 & 379.72 & 380.35 & 396.43 & 378.49 & 378.56 & 370.27 & 378.25 & 383.99 & 489.28 & 399.52 & 489.28 & 399.52 & 489.28 & 399.52 & 399.52 & 489.28 & 399.52 \\
\hline $\mathrm{P}_{19}$ & 369.66 & 380.14 & 376.71 & 383.11 & 376.05 & 380.13 & 514.11 & 381.48 & 380.53 & 421.52 & 511.28 & 421.55 & 511.28 & 421.52 & 511.28 & 511.28 & 511.28 & 511.28 \\
\hline $\mathrm{P}_{20}$ & 510.86 & 514.48 & 381.93 & 418.77 & 377.37 & 379.99 & 378.16 & 421.36 & 380.39 & 421.52 & 421.52 & 511.29 & 421.52 & 511.28 & 511.28 & 421.52 & 511.28 & 421.52 \\
\hline$P_{21}$ & 507.27 & 377.87 & 379.89 & 374.86 & 514.91 & 378.18 & 386.26 & 384.22 & 378.25 & 523.28 & 433.52 & 523.31 & 523.28 & 523.28 & 433.52 & 523.28 & 523.28 & 438.64 \\
\hline$P_{22}$ & 359.22 & 512.72 & 385.18 & 494.32 & 386.84 & 379.08 & 442.63 & 421.33 & 381.37 & 433.52 & 523.28 & 523.30 & 433.52 & 523.28 & 433.52 & 523.28 & 523.28 & 523.28 \\
\hline$P_{23}$ & 377.36 & 380.61 & 382.38 & 392.60 & 516.35 & 375.06 & 439.89 & 378.91 & 513.87 & 433.52 & 433.52 & 523.27 & 523.28 & 523.28 & 523.28 & 523.28 & 523.28 & 523.28 \\
\hline $\mathrm{P}_{24}$ & 382.14 & 376.36 & 378.39 & 381.61 & 378.81 & 516.50 & 523.65 & 474.95 & 379.06 & 523.28 & 523.28 & 523.28 & 523.28 & 523.28 & 523.28 & 523.28 & 433.52 & 523.28 \\
\hline $\mathrm{P}_{25}$ & 369.11 & 377.69 & 379.76 & 378.90 & 378.52 & 383.25 & 387.77 & 476.45 & 378.13 & 433.52 & 523.28 & 523.29 & 523.28 & 523.28 & 523.28 & 523.28 & 523.28 & 523.28 \\
\hline $\mathrm{P}_{26}$ & 491.53 & 382.72 & 517.24 & 336.93 & 378.61 & 378.28 & 369.65 & 378.45 & 380.07 & 523.28 & 523.28 & 523.28 & 523.28 & 523.28 & 523.28 & 523.28 & 523.28 & 523.28 \\
\hline $\mathrm{P}_{27}$ & 93.45 & 93.48 & 92.83 & 92.98 & 93.43 & 94.42 & 93.58 & 92.49 & 93.10 & 87.80 & 97.00 & 87.89 & 87.80 & 87.80 & 87.80 & 87.80 & 47.00 & 97.00 \\
\hline $\mathrm{P}_{28}$ & 182.05 & 186.33 & 185.87 & 183.07 & 186.43 & 185.37 & 182.88 & 185.91 & 184.05 & 190.00 & 190.00 & 190.00 & 190.00 & 190.00 & 190.00 & 190.00 & 190.00 & 190.00 \\
\hline $\mathrm{P}_{29}$ & 186.87 & 186.43 & 186.05 & 186.34 & 186.44 & 187.64 & 187.78 & 186.05 & 185.87 & 190.00 & 190.00 & 190.00 & 190.00 & 190.00 & 190.00 & 190.00 & 190.00 & 190.00 \\
\hline $\mathrm{P}_{30}$ & 189.23 & 186.47 & 185.33 & 186.56 & 186.43 & 185.37 & 181.57 & 185.14 & 187.15 & 190.00 & 190.00 & 190.00 & 190.00 & 190.00 & 190.00 & 190.00 & 190.00 & 190.00 \\
\hline $\mathrm{P}_{31}$ & 199.59 & 196.47 & 195.85 & 199.89 & 196.43 & 197.29 & 196.01 & 196.80 & 196.10 & 200.00 & 200.00 & 193.39 & 200.00 & 185.94 & 164.80 & 164.80 & 164.80 & 200.00 \\
\hline $\mathrm{P}_{32}$ & 194.80 & 194.73 & 194.75 & 198.31 & 197.43 & 195.97 & 195.80 & 196.88 & 196.32 & 200.00 & 200.00 & 200.00 & 200.00 & 200.00 & 198.88 & 164.80 & 194.80 & 200.00 \\
\hline $\mathrm{P}_{33}$ & 191.83 & 197.48 & 196.88 & 199.74 & 195.43 & 195.41 & 196.11 & 196.63 & 196.16 & 200.00 & 200.00 & 200.00 & 200.00 & 200.00 & 200.00 & 164.80 & 200.00 & 200.00 \\
\hline $\mathrm{P}_{34}$ & 104.06 & 106.45 & 107.13 & 104.28 & 106.43 & 106.42 & 106.60 & 105.88 & 106.07 & 110.00 & 110.00 & 110.00 & 110.00 & 110.00 & 110.00 & 110.00 & 110.00 & 110.00 \\
\hline $\mathrm{P}_{35}$ & 104.09 & 107.43 & 106.76 & 105.89 & 106.43 & 106.29 & 98.74 & 105.98 & 105.74 & 110.00 & 110.00 & 110.00 & 110.00 & 110.00 & 110.00 & 110.00 & 110.00 & 110.00 \\
\hline $\mathrm{P}_{36}$ & 107.07 & 106.41 & 105.67 & 109.77 & 106.43 & 107.29 & 102.26 & 106.43 & 108.01 & 110.00 & 110.00 & 110.00 & 110.00 & 110.00 & 110.00 & 110.00 & 110.00 & 110.00 \\
\hline $\mathrm{P}_{37}$ & 377.79 & 378.89 & 515.38 & 505.45 & 377.28 & 512.67 & 381.81 & 377.41 & 514.16 & 511.28 & 511.28 & 511.26 & 511.28 & 511.28 & 511.28 & 421.52 & 511.28 & 511.28 \\
\hline $\mathrm{P}_{38}$ & 25.70 & 144.48 & 142.06 & 89.64 & 146.43 & 143.89 & 10.08 & 145.00 & 143.06 & 10.00 & 10.00 & 10.00 & 10.00 & 10.00 & 10.00 & 10.00 & 10.00 & 10.00 \\
\hline $\begin{array}{l}P_{39} \\
P_{3}\end{array}$ & 10.00 & 144.48 & 138.94 & 125.33 & 144.43 & 139.23 & 123.60 & 105.01 & 142.86 & 10.00 & 10.00 & 10.00 & 10.00 & 10.00 & 10.00 & 10.00 & 10.00 & 10.00 \\
\hline $\mathrm{P}_{40}$ & 132.07 & 10.04 & 10.02 & 16.68 & 10.00 & 10.04 & 68.18 & 48.95 & 10.01 & 10.00 & 10.00 & 10.00 & 10.00 & 10.00 & 10.00 & 10.00 & 10.00 & 10.00 \\
\hline
\end{tabular}




\section{References}

1. Stoft, S. Power system economics. J. Energy Lit. 2002, 8, 94-99.

2. Akkaş, Ö.P.; Çam, E.; Eke, İ.; Arikan, Y. New Optimization Algorithms for Application to Environmental Economic Load Dispatch in Power Systems. Electrica 2018, 18, 133-142. [CrossRef]

3. Chouhdry, Z.R.; Hasan, K.M.; Raja, M.A.Z. Design of reduced search space strategy based on integration of Nelder-Mead method and pattern search algorithm with application to economic load dispatch problem. Neural Comput. Appl. 2018, 30, 3693-3705. [CrossRef]

4. Zou, D.; Li, S.; Wang, G.G.; Li, Z.; Ouyang, H. An improved differential evolution algorithm for the economic load dispatch problems with or without valve-point effects. Appl. Energy 2016, 181, 375-390. [CrossRef]

5. Zakian, P.; Kaveh, A. Economic dispatch of power systems using an adaptive charged system search algorithm. Appl. Soft Comput. 2018, 73, 607-622. [CrossRef]

6. Chen, W.H.; Wu, P.H.; Lin, Y.L. Performance optimization of thermoelectric generators designed by multi-objective genetic algorithm. Appl. Energy 2018, 209, 211-223. [CrossRef]

7. Roy, P.K.; Ghoshal, S.P.; Thakur, S.S. Biogeography-based optimization for economic load dispatch problems. Electr. Power Compon. Syst. 2009, 38, 166-181. [CrossRef]

8. Chen, X.; Xu, B.; Mei, C.; Ding, Y.; Li, K. Teaching-learning-based artificial bee colony for solar photovoltaic parameter estimation. Appl. Energy 2018, 212, 1578-1588. [CrossRef]

9. Pradhan, M.; Roy, P.K.; Pal, T. Grey wolf optimization applied to economic load dispatch problems. Int. J. Electr. Power Energy Syst. 2016, 83, 325-334. [CrossRef]

10. Kamboj, V.K.; Bhadoria, A.; Bath, S.K. Solution of non-convex economic load dispatch problem for small-scale power systems using ant lion optimizer. Neural Comput. Appl. 2017, 28, 2181-2192. [CrossRef]

11. Chen, G.; Lu, Z.; Zhang, Z. Improved krill herd algorithm with novel constraint handling method for solving optimal power flow problems. Energies 2018, 11, 76. [CrossRef]

12. Mandal, B.; Roy, P.K.; Mandal, S. Economic load dispatch using krill herd algorithm. Int. J. Electr. Power Energy Syst. 2014, 57, 1-10. [CrossRef]

13. Al-Betar, M.A.; Awadallah, M.A.; Khader, A.T.; Bolaji, A.L.A.; Almomani, A. Economic load dispatch problems with valve-point loading using natural updated harmony search. Neural Comput. Appl. 2016, 1-15. [CrossRef]

14. Jebaraj, L.; Venkatesan, C.; Soubache, I.; Rajan, C.C.A. Application of differential evolution algorithm in static and dynamic economic or emission dispatch problem: A review. Renew. Sustain. Energy Rev. 2017, 77, 1206-1220. [CrossRef]

15. Ali, E.S.; Elazim, S.A. Mine blast algorithm for environmental economic load dispatch with valve loading effect. Neural Comput. Appl. 2018, 30, 261-270. [CrossRef]

16. Mohammad, F.; Abdi, H. A modified crow search algorithm (MCSA) for solving economic load dispatch problem. Appl. Soft Comput. 2018, 71, 51-65. [CrossRef]

17. Dosoglu, M.K.; Guvenc, U.; Duman, S.; Sonmez, Y.; Kahraman, H.T. Symbiotic organisms search optimization algorithm for economic/emission dispatch problem in power systems. Neural Comput. Appl. 2018, 29, 721-737. [CrossRef]

18. Ziane, I.; Benhamida, F.; Graa, A. Simulated annealing algorithm for combined economic and emission power dispatch using max/max price penalty factor. Neural Comput. Appl. 2017, 28, 197-205. [CrossRef]

19. Roy, P.K.; Bhui, S. A multi-objective hybrid evolutionary algorithm for dynamic economic emission load dispatch. Int. Trans. Electr. Energy Syst. 2016, 26, 49-78. [CrossRef]

20. Ma, H.; Yang, Z.; You, P.; Fei, M. Multi-objective biogeography-based optimization for dynamic economic emission load dispatch considering plug-in electric vehicles charging. Energy 2017, 135, 101-111. [CrossRef]

21. Abdelaziz, A.Y.; Ali, E.S.; Elazim, S.A. Implementation of flower pollination algorithm for solving economic load dispatch and combined economic emission dispatch problems in power systems. Energy 2016, 101, 506-518. [CrossRef]

22. Jadoun, V.K.; Gupta, N.; Niazi, K.R.; Swarnkar, A. Modulated particle swarm optimization for economic emission dispatch. Int. J. Electr. Power Energy Syst. 2015, 73, 80-88. [CrossRef]

23. Adarsh, B.R.; Raghunathan, T.; Jayabarathi, T.; Yang, X.S. Economic dispatch using chaotic bat algorithm. Energy 2016, 96, 666-675. [CrossRef] 
24. Wang, W.; Li, C.; Liao, X.; Qin, H. Study on unit commitment problem considering pumped storage and renewable energy via a novel binary artificial sheep algorithm. Appl. Energy 2017, 187, 612-626. [CrossRef]

25. Morshed, M.J.; Asgharpour, A. Hybrid imperialist competitive sequential quadratic programming (HIC-SQP) algorithm for solving economic load dispatch with incorporating stochastic wind power: A comparative study on heuristic optimization techniques. Energy Convers. Manag. 2014, 84, 30-40. [CrossRef]

26. Teeparthi, K.; Kumar, D.V. Security-constrained optimal power flow with wind and thermal power generators using fuzzy adaptive artificial physics optimization algorithm. Neural Comput. Appl. 2018, 29, 855-871. [CrossRef]

27. Safari, A.; Shahsavari, H. Frequency-constrained unit commitment problem with considering dynamic ramp rate limits in the presence of wind power generation. Neural Comput. Appl. 2018, 1-14. [CrossRef]

28. Qu, B.Y.; Liang, J.J.; Zhu, Y.S.; Wang, Z.Y.; Suganthan, P.N. Economic emission dispatch problems with stochastic wind power using summation based multi-objective evolutionary algorithm. Inf. Sci. 2016, 351, 48-66. [CrossRef]

29. Li, M.S.; Lin, Z.J.; Ji, T.Y.; Wu, Q.H. Risk constrained stochastic economic dispatch considering dependence of multiple wind farms using pair-copula. Appl. Energy 2018, 226, 967-978. [CrossRef]

30. Khan, W.U.; Ye, Z.; Chaudhary, N.I.; Raja, M.A.Z. Backtracking search integrated with sequential quadratic programming for nonlinear active noise control systems. Appl. Soft Comput. 2018, 73, 666-683. [CrossRef]

31. Raja, M.A.Z.; Ahmed, T.; Shah, S.M. Intelligent computing strategy to analyze the dynamics of convective heat transfer in MHD slip flow over stretching surface involving carbon nanotubes. J. Taiwan Inst. Chem. Eng. 2017, 80, 935-953. [CrossRef]

32. Ahmad, I.; Ahmad, S.; Awais, M.; Ahmad, S.U.I.; Raja, M.A.Z. Neuro-evolutionary computing paradigm for Painlevé equation-II in nonlinear optics. Eur. Phys. J. Plus 2018, 133, 184. [CrossRef]

33. Sabir, Z.; Manzar, M.A.; Raja, M.A.Z.; Sheraz, M.; Wazwaz, A.M. Neuro-heuristics for nonlinear singular Thomas-Fermi systems. Appl. Soft Comput. 2018, 65, 152-169. [CrossRef]

34. Umar, M.; Sabir, Z.; Raja, M.A.Z. Intelligent computing for numerical treatment of nonlinear prey-predator models. Appl. Soft Comput. 2019, 80, 506-524. [CrossRef]

35. Raja, M.A.Z.; Sabir, Z.; Mehmood, N.; Al-Aidarous, E.S.; Khan, J.A. Design of stochastic solvers based on genetic algorithms for solving nonlinear equations. Neural Comput. Appl. 2015, 26, 1-23. [CrossRef]

36. Raja, M.A.Z.; Kiani, A.K.; Shehzad, A.; Zameer, A. Memetic computing through bio-inspired heuristics integration with sequential quadratic programming for nonlinear systems arising in different physical models. SpringerPlus 2016, 5, 2063. [CrossRef] [PubMed]

37. Javadi, M.; Marzband, M.; Funsho Akorede, M.; Godina, R.; Saad Al-Sumaiti, A.; Pouresmaeil, E. A centralized smart decision-making hierarchical interactive architecture for multiple home microgrids in retail electricity market. Energies 2018, 11, 3144. [CrossRef]

38. Valinejad, J.; Marzband, M.; Funsho Akorede, M.; D Elliott, I.; Godina, R.; Matias, J.; Pouresmaeil, E. Long-term decision on wind investment with considering different load ranges of power plant for sustainable electricity energy market. Sustainability 2018, 10, 3811. [CrossRef]

39. Valinejad, J.; Barforoshi, T.; Marzband, M.; Pouresmaeil, E.; Godina, R.; PS Catalão, J. Investment Incentives in Competitive Electricity Markets. Appl. Sci. 2018, 8, 1978. [CrossRef]

40. Marzband, M.; Azarinejadian, F.; Savaghebi, M.; Pouresmaeil, E.; Guerrero, J.M.; Lightbody, G. Smart transactive energy framework in grid-connected multiple home microgrids under independent and coalition operations. Renew. Energy 2018, 126, 95-106. [CrossRef]

41. Holland, J.H. Genetic algorithms. Sci. Am. 1992, 267, 66-73. [CrossRef]

42. Wang, S.; Zhao, F.; Liu, Z.; Hao, H. Heuristic method for automakers' technological strategy making towards fuel economy regulations based on genetic algorithm: A China's case under corporate average fuel consumption regulation. Appl. Energy 2018, 204, 544-559. [CrossRef]

43. Ferdyn-Grygierek, J.; Grygierek, K. Multi-variable optimization of building thermal design using genetic algorithms. Energies 2017, 10, 1570. [CrossRef]

44. Alcayde, A.; Baños, R.; Arrabal-Campos, F.M.; Montoya, F.G. Optimization of the Contracted Electric Power by Means of Genetic Algorithms. Energies 2019, 12, 1270. [CrossRef]

45. Kim, H.; Park, H. Nonnegative matrix factorization based on alternating nonnegativity constrained least squares and active set method. SIAM J. Matrix Anal. Appl. 2008, 30, 713-730. [CrossRef] 
46. Krishnan, D.; Lin, P.; Yip, A.M. A primal-dual active-set method for non-negativity constrained total variation deblurring problems. IEEE Trans. Image Process. 2007, 16, 2766-2777. [CrossRef] [PubMed]

47. Abo-Elnaga, Y.; El-Sobky, B.; Al-Naser, L. An active-set trust-region algorithm for solving warehouse location problem. J. Taibah Univ. Sci. 2017, 11, 353-358. [CrossRef]

48. Sinha, N.; Chakrabarti, R.; Chattopadhyay, P.K. Evolutionary programming techniques for economic load dispatch. IEEE Trans. Evol. Comput. 2003, 7, 83-94. [CrossRef]

49. Azizipanah-Abarghooee, R.; Niknam, T.; Roosta, A.; Malekpour, A.R.; Zare, M. Probabilistic multiobjective wind-thermal economic emission dispatch based on point estimated method. Energy 2012, 37, 322-335. [CrossRef]

50. Khodabakhshian, A.; Pour, M.E.; Hooshmand, R. Design of a robust load frequency control using sequential quadratic programming technique. Int. J. Electr. Power Energy Syst. 2012, 40, 1-8. [CrossRef]

51. Attaviriyanupap, P.; Kita, H.; Tanaka, E.; Hasegawa, J. A hybrid EP and SQP for dynamic economic dispatch with nonsmooth fuel cost function. IEEE Trans. Power Syst. 2002, 17, 411-416. [CrossRef]

52. Pothiya, S.; Ngamroo, I.; Kongprawechnon, W. Ant colony optimisation for economic dispatch problem with non-smooth cost functions. Int. J. Electr. Power Energy Syst. 2010, 32, 478-487. [CrossRef]

53. Bhattacharya, A.; Chattopadhyay, P.K. Solving complex economic load dispatch problems using biogeography-based optimization. Expert Syst. Appl. 2010, 37, 3605-3615. [CrossRef]

54. Panigrahi, B.K.; Pandi, V.R. Bacterial foraging optimisation: Nelder-Mead hybrid algorithm for economic load dispatch. IET Gener. Transm. Distrib. 2008, 2, 556-565. [CrossRef]

55. Selvakumar, A.I.; Thanushkodi, K. A new particle swarm optimization solution to nonconvex economic dispatch problems. IEEE Trans. Power Syst. 2007, 22, 42-51. [CrossRef]

56. Amjady, N.; Nasiri-Rad, H. Nonconvex economic dispatch with AC constraints by a new real coded genetic algorithm. IEEE Trans. Power Syst. 2009, 24, 1489-1502. [CrossRef]

(C) 2019 by the authors. Licensee MDPI, Basel, Switzerland. This article is an open access article distributed under the terms and conditions of the Creative Commons Attribution (CC BY) license (http://creativecommons.org/licenses/by/4.0/). 